\title{
Rapid Vesicular Release, Quantal Variability, and Spillover Contribute to the Precision and Reliability of Transmission at a Glomerular Synapse
}

\author{
Peter B. Sargent, ${ }^{2}$ Chiara Saviane, ${ }^{1}$ Thomas A. Nielsen, ${ }^{1}$ David A. DiGregorio, ${ }^{1}$ and R. Angus Silver ${ }^{1}$ \\ ${ }^{1}$ Department of Physiology, University College London, London WC1E 6BT, United Kingdom, and ${ }^{2}$ Department of Cell and Tissue Biology, University of \\ California, San Francisco, San Francisco, California 94143-0640
}

\begin{abstract}
The amplitude and shape of EPSC waveforms are thought to be important determinants of information processing and storage in the brain, yet relatively little is known about the origins of EPSC variability or how it affects synaptic signaling. We investigated the stochastic determinants of AMPA receptor-mediated EPSC variability at cerebellar mossy fiber-granule cell (MF-GC) connections by combining multiple-probability fluctuation analysis (MPFA) and deconvolution methods. The properties of MF connections with a single release site and the effects of the rapidly equilibrating competitive antagonist kynurenic acid on EPSCs suggest that receptors are not saturated by glutamate during a quantal event and that quanta sum linearly over a wide range of release probabilities. MPFA revealed an average of five vesicular release sites per MF-GC connection. Our results show that the time course of vesicular release is rapid (decay, $\tau=75 \mu$ s) and independent of release probability, introducing little jitter in the shape or timing of the quantal component of the EPSC at physiological temperature. Moreover, the peak vesicular release rate per release site after an action potential (AP) $\left(\sim 3 \mathrm{~ms}^{-1}\right)$ is substantially higher than previously reported for central synapses. Interaction of amplitude fluctuations arising from quantal release and quantal size with the slower, low variability spillover-mediated current produce substantial variability in EPSC shape. Our simulations of MF-GC transmission suggest that quantal variability and transmitter spillover extend the voltage from which AP threshold can be crossed, improving reliability, and that fast vesicular release allows precise signaling across MF connections with heterogeneous weights.
\end{abstract}

Key words: release rate; vesicle; quantal; spillover; stochastic; synapse

\section{Introduction}

Differences in the amplitude of synaptic currents are thought to contribute to the processing and storage of information in neural networks. In addition, the time course of EPSCs determines the precision and reliability of signaling (Harsch and Robinson, 2000; Galarreta and Hestrin, 2001; Cathala et al., 2003) and influences the gain of rate-coded input-output relationships (Mitchell and Silver, 2003). These findings show that the mean properties of the synaptic current waveform are important for signal processing. However, individual PSCs often deviate significantly from the mean behavior, exhibiting large trial-to-trial variability (Traynelis et al., 1993; Bekkers and Clements, 1999; Nusser et al., 2001), yet little is known about how such stochastic behavior influences transmission. Knowledge of the processes that underlie trial-to-trial EPSC variability is important for understanding signal processing because they are likely to deter-

Received May 20, 2005; revised July 1, 2005; accepted July 1, 2005

This work was supported by the Wellcome Trust and European Commission. R.A.S. is in receipt of a Wellcome Trust Senior Fellowship. T.A.N. was supported by the Wellcome Trust graduate program. We thank Wade Regehr for providing the deconvolution algorithm and David Attwell, Mark Farrant, and Volker Steuber for comments on this manuscript.

Correspondence should be addressed to Dr. R. A. Silver, Department of Physiology, University College London, Gower Street, London WC1E 6BT, UK. E-mail: a.silver@ucl.ac.uk.

DOI:10.1523/JNEUROSCI.2051-05.2005

Copyright $\odot 2005$ Society for Neuroscience $\quad$ 0270-6474/05/258173-15\$15.00/0 mine the precision and reliability of transmission and thus the rate at which information can be transmitted (Zador, 1998).

Four parameters are thought to be particularly important in determining trial-to-trial EPSC variability: the time course and probability of quantal release, the number of release sites, and the quantal size, which is the postsynaptic response to a single vesicle (Katz, 1969; Sun et al., 2002). Previous studies have quantified the determinants of the mean EPSC waveform by using deconvolution methods to estimate the time course of vesicular release (Diamond and Jahr, 1995; Isaacson and Walmsley, 1995; Borst and Sakmann, 1996; Geiger et al., 1997; Schneggenburger and Neher, 2000). However, quantifying the origins and assessing the impact of EPSC variability has been complicated by uncertainty about whether multiple vesicles [multivesicular release (Wadiche and Jahr, 2001; Oertner et al., 2002)] are released per synaptic contact per action potential (AP), because this can cause postsynaptic saturation [full receptor occupancy (Foster et al., 2002; Harrison and Jahr, 2003)] and thus introduce nonlinear quantal summation.

We investigated the key determinants of AMPA receptor (AMPAR)-mediated EPSC amplitude and shape variability within and across connections at the cerebellar mossy fibergranule cell (MF-GC) synapse at physiological temperature. This preparation is well suited to the study of vesicular release and EPSC variability because GCs have a compact morphology and a 
small number of inputs, allowing EPSC recordings to be made from individual synaptic connections with exceptional temporal resolution (Silver et al., 1996b). Both direct vesicular release and glutamate spillover contribute to the EPSC waveform at this glomerular synapse (DiGregorio et al., 2002; Nielsen et al., 2004). We used competitive antagonist techniques to probe the linearity of quantal summation at MF connections (Wadiche and Jahr, 2001; Silver et al., 2003). By combining multiple-probability fluctuation analysis (MPFA) (Silver et al., 1998; Silver, 2003) and deconvolution (Diamond and Jahr, 1995; Isaacson and Walmsley, 1995; Borst and Sakmann, 1996; Geiger et al., 1997), we determined the time course and probability of vesicular release, the number of release sites, the quantal size, and the properties of spillover currents at each connection. By constructing stochastic models of transmission for individual MG-GC connections, we show that rapid vesicular release, quantal variability, and spillover currents introduce considerable EPSP variability and influence precision and reliability of MF-GC synaptic signaling.

\section{Materials and Methods}

Parasagittal slices of cerebellum were prepared from 25-d-old Sprague Dawley rats as described previously (Silver et al., 1996b). Slices (200-250 $\mu \mathrm{m})$ were prepared in either artificial CSF (ACSF) $(126 \mathrm{~mm} \mathrm{NaCl}, 2.5 \mathrm{~mm}$ $\mathrm{KCl}, 26 \mathrm{~mm} \mathrm{NaHCO}_{3}, 25 \mathrm{~mm}$ glucose, $2 \mathrm{~mm} \mathrm{CaCl}_{2}, 1.25 \mathrm{~mm} \mathrm{NaH}_{2} \mathrm{PO}_{4}$, and $1 \mathrm{mM} \mathrm{MgCl}_{2}$, pH 7.4 when bubbled with $95 \% \mathrm{O}_{2}, 5 \% \mathrm{CO}_{2}$ ) or a low sodium-sucrose solution (in mM: $85 \mathrm{NaCl}, 2.5 \mathrm{KCl}, 25 \mathrm{NaHCO}_{3}, 1.25$ $\mathrm{NaH}_{2} \mathrm{PO}_{4}$, 64 sucrose, 25 glucose, $0.5 \mathrm{CaCl}_{2}, 4 \mathrm{MgCl}_{2}$, and 0.5 ascorbic acid) and incubated at $30-31^{\circ} \mathrm{C}$ for $30-45 \mathrm{~min}$. Slices were then transferred to ACSF or ACSF containing $1 \mathrm{~mm}$ kynurenic acid (Kyn) and stored at room temperature for up to $6 \mathrm{~h}$ before use.

Synaptic recordings. Slices were perfused at $2 \mathrm{ml} / \mathrm{min}$ with ACSF containing $10 \mu \mathrm{M}$ D-APV, $20 \mu \mathrm{M}$ 7-chlorokynurenic acid, $0.3 \mu \mathrm{M}$ strychnine, and $10 \mu \mathrm{M}$ SR95531 ("gabazine") and viewed using infrared differential interference contrast optics. The osmolarity of ACSF containing different divalent ion concentrations $\left(\left[\mathrm{Ca}^{2+}\right] /\left[\mathrm{Mg}^{2+}\right]\right.$ in $\mathrm{mm}: 1 / 5,1.25 / 3$, $1.5 / 2,2 / 1,3 / 0.75,5 / 0.5$, and $8 / 0$ ) was kept constant by varying [glucose] between 10 and $25 \mathrm{~mm}$. In some experiments, $\mathrm{NaH}_{2} \mathrm{PO}_{4}$ was omitted from the ACSF. Kynurenic acid was added alone or together with cyclothiazide to test for multiquantal release or to reduce AMPA receptor desensitization, respectively. Granule cells were patched with firepolished pipettes containing $110 \mathrm{~mm} \mathrm{KMeSO}_{4}, 40 \mathrm{~mm}$ HEPES, $4 \mathrm{~mm}$ $\mathrm{NaCl}, 1 \mathrm{~mm} \mathrm{KCl}, 0.5$ mm EGTA, 4 mm MgATP, and 0.3 mм MgGTP (or a variant that contained $1.78 \mathrm{mM} \mathrm{CaCl}_{2}$ and $5 \mathrm{~mm}$ EGTA) that had resistances of 8-10 $\mathrm{M} \Omega$. Whole-cell voltage-clamp recordings were made at $-70 \mathrm{mV}$ using an Axopatch 200B amplifier (Molecular Devices, Union City, CA) at $36.6 \pm 1.3^{\circ} \mathrm{C}$. Current records were low-pass filtered at $7-10$ $\mathrm{kHz}$ and digitized at $100 \mathrm{kHz}$ (Digidata 1200; Molecular Devices). Access resistance was monitored continuously, and recordings were discarded if the access resistance exceeded $35 \mathrm{M} \Omega$. Single MF inputs were stimulated with brief voltage pulses $2.5-5 \mathrm{~V}$ above threshold using a second patch pipette filled with ACSF and placed in the GC layer (Silver et al., 1996b). Because fiber excitability is influenced by $\left[\mathrm{Ca}^{2+}\right]$, we measured the stimulation threshold and reset the stimulation voltage when the $\left[\mathrm{Ca}^{2+}\right]$ was altered. To maximize the number of synaptic events in the three to five different $\left[\mathrm{Ca}^{2+}\right] /\left[\mathrm{Mg}^{2+}\right]$ conditions used per cell, we used the fastest stimulation rate that did not introduce depression (typically $2 \mathrm{~Hz}$ at low $\left[\mathrm{Ca}^{2+}\right], 0.5 \mathrm{~Hz}$ at $2 \mathrm{~mm}\left[\mathrm{Ca}^{2+}\right]$, and $0.2 \mathrm{~Hz}$ at $\left.5-8 \mathrm{~mm}\left[\mathrm{Ca}^{2+}\right]\right)$. Recordings were analyzed in Igor PRO (Wavemetrics, Lake Oswego, OR) using NeuroMatic (http://www.physiol.ucl.ac.uk/research/silver_a/neuromatic/). All traces displayed in the figures were further digitally filtered to $3.5 \mathrm{kHz}$ using the binomial smoothing function in Igor PRO.

Analysis and sorting of EPSCs. The stimulus artifact was removed by subtracting a double-exponential fit to the decay of the artifact current. Individual traces were baseline subtracted using a $0.5-1.0 \mathrm{~ms}$ window (see Fig. $3 A$ ) ending immediately before the stimulus, and successes and failures were distinguished using an amplitude criterion set to three times the SD of the noise. Successes were then separated into fast-rising direct responses and slow-rising spillover synaptic events on the basis of their rise time and maximum rate of rise, as described previously (DiGregorio et al., 2002). Slowly rising events and failures were grouped together and classified as nondirect. The shape of EPSCs was quantified by calculating an approximate weighted decay from the integral of the peak-normalized current. For some analyses, current waveforms were fitted with an expression (Nielsen et al., 2004) modified from Bekkers and Stevens (1996):

$$
\begin{aligned}
\operatorname{EPSC}(t)=A_{1}\left(1-\exp \left(-\frac{t-t_{0}}{\tau_{\text {rise }}}\right)\right)^{n}\left(A_{2} \exp \left(-\frac{t-t_{0}}{\tau_{\text {decay } 1}}\right)\right. \\
\left.+\left(1-A_{2}\right) \exp \left(-\frac{t-t_{0}}{\tau_{\text {decay } 2}}\right)\right) .
\end{aligned}
$$

Means are displayed \pm SD. Unless otherwise indicated, sample means were compared using the Student's $t$ test, sample distributions were compared using the Kolmogorov-Smirnov test, and the correlation between samples was tested by measuring Pearson's $r$.

Multiple-probability fluctuation analysis and quantal variability. MPFA was performed as described previously (Silver et al., 1998; Silver, 2003) on epochs of EPSCs determined to be stable by Spearman's rank order correlation test (Silver et al., 1996b). Mean current and backgroundcorrected variance were calculated from a fixed $0.1 \mathrm{~ms}$ time windows placed over the mean peak response of the direct events (see below) and in the pre-event baseline (see Fig. $3 A$ ). The relationship between variance $\left(\sigma_{I}^{2}\right)$ and mean $(\bar{I})$ current for each connection was fit with a multinomial model (Silver, 2003) with either a uniform

$$
\sigma_{I}^{2}=\left[\mathrm{Q}_{P} \bar{I}-\frac{\bar{I}^{2}}{N}\right]\left(1+\mathrm{CV}_{\mathrm{QII}}^{2}\right)+Q_{P} \bar{I} \mathrm{CV}_{\mathrm{QI}}^{2}
$$

or non-uniform

$$
\sigma_{I}^{2}=\left[Q_{\mathrm{P}} \bar{I}-\frac{Q_{\mathrm{P}} \bar{I}^{2}(1+\alpha)}{\bar{I}+N Q_{\mathrm{P}} \alpha}\right]\left(1+\mathrm{CV}_{\mathrm{QII}}^{2}\right)+Q_{\mathrm{P}} \bar{I} \mathrm{CV}_{\mathrm{QI}}^{2}
$$

release probability, where $Q_{\mathrm{P}}$ is the mean quantal size at the time of the peak of the direct response, $N$ is the number of release sites, and $\alpha$ is a variable that relates to the coefficient of variation of release probability $\left(\mathrm{CV}_{\mathrm{PR}}\right)$, where

$$
\mathrm{CV}_{\mathrm{PR}}=\sqrt{\frac{1-P_{\mathrm{R}}}{P_{\mathrm{R}}+\alpha}}
$$

and where release probability, $P_{\mathrm{R}}$, was calculated by dividing $\bar{I}$ by $N Q_{\mathrm{P}}$. $\mathrm{CV}_{\mathrm{QI}}$ and $\mathrm{CV}_{\mathrm{QII}}$ are the coefficients of variation of intrasite and intersite quantal variability (Silver, 2003). $\mathrm{CV}_{\mathrm{QI}}$ itself has two components, so that the total quantal variability $\mathrm{CV}_{\mathrm{QT}}$ can be expressed as

$$
\mathrm{CV}_{\mathrm{QT}}=\sqrt{\mathrm{CV}_{\mathrm{QI}}^{2}+\mathrm{CV}_{\mathrm{QII}}^{2}}=\sqrt{\mathrm{CV}_{\mathrm{QS}}^{2}+\mathrm{CV}_{\mathrm{QL}}^{2}+\mathrm{CV}_{\mathrm{QII}}^{2}}
$$

where $\mathrm{CV}_{\mathrm{QS}}$ arises from variability in the quantal size at an individual site, and $\mathrm{CV}_{\mathrm{OL}}$ arises from jitter in the latency of quantal release. We measured $\mathrm{CV}_{\mathrm{QT}}(0.49 ; n=14)$ directly from stimulus-aligned EPSCs recorded from multisite MF inputs under low release probability, when the proportion of multiquantal EPSCs is negligible ( $~ 5 \%$ based on $N$ and failure rate $f>0.85$ ) (Silver, 2003). We initially determined $\mathrm{CV}_{\mathrm{QL}}$ from the difference in variability of stimulus-aligned and rise time-aligned uniquantal EPSCs $(0.29 ; n=14)$. To minimize the effects of sampling error, we also estimated $\mathrm{CV}_{\mathrm{QL}}$ by simulating stochastic quantal release at a release site with 10,000 trials using the mean measured quantal waveform and the mean latency distribution measured from 17 cells under low probability conditions: this approach gave a similar estimate of $\mathrm{CV}_{\mathrm{QL}}$ (0.28). $\mathrm{CV}_{\mathrm{QS}}$ was more difficult to estimate because we encountered only two single-site MF inputs in our sample and because the average $\mathrm{CV}$ for rise-aligned events for these two connections $(0.32)$ was higher than $\mathrm{CV}_{\mathrm{QT}}$ for 3 of the 14 multisite connections examined, indicating that $\mathrm{CV}_{\mathrm{QS}}$ at some multisite connections was lower than the mean for the single sites. We therefore used a lower value of $\mathrm{CV}_{\mathrm{QS}}(0.26)$ that fell 
midway between this estimate and the estimate for four single-site cells we characterized previously in younger animals (0.21) (Silver et al., 1996b). Finally, we calculated $\mathrm{CV}_{\mathrm{QII}}$ to be 0.31 , from Equation 5 . If quanta are independent, then the variance remaining at the peak of an evoked EPSC as $P_{\mathrm{R}} \rightarrow 1$ should arise purely from intrasite quantal amplitude variability and quantal asynchrony (Silver et al., 1998; Clements and Silver, 2000; Silver, 2003). Calculation of $\mathrm{CV}_{\mathrm{QI}}$ from $N$ and from variance remaining at $8 \mathrm{~mm}\left[\mathrm{Ca}^{2+}\right]$ gave a value $(0.39 \pm 0.12 ; n=17)$ that is similar to our estimate of

$$
\sqrt{\mathrm{CV}_{\mathrm{QS}}^{2}+\mathrm{CV}_{\mathrm{QL}}^{2}} \text {. }
$$

The quantal parameters $Q_{\mathrm{P}}$ and $N$ were estimated from weighted fits of Equations 2 and 3 to variance-mean relationships (Silver, 2003). Fits were accepted if the $\chi^{2}$ statistic was smaller than the threshold for rejecting the null hypothesis at $p=0.05$ (which required $\geq 3$ points for Eq. 2 and $\geq 4$ points for Eq. 3 ) and if the release probability at the highest $\left[\mathrm{Ca}^{2+}\right]$ used was $>0.60$, which ensures accurate estimation of $N$ (Silver, 2003).

Spillover current correction for MPFA and characterization of spillover for simulations. To estimate the quantal parameters underlying the EPSC with MPFA, it was necessary to correct the mean and variance of the current at the peak of the quantal component for the contribution arising from glutamate spillover. Because spillover currents can affect the time of the peak of the EPSC, we determined the time of the peak of the quantal (direct) component at low $\left[\mathrm{Ca}^{2+}\right](1$ or $1.25 \mathrm{~mm})$, when there is little spillover current (DiGregorio et al., 2002). The calculated peak of the direct response was as much as $0.09 \mathrm{~ms}$ earlier than the actual peak of the EPSC at $2 \mathrm{~mm}\left[\mathrm{Ca}^{2+}\right]$ (average; $0.02 \mathrm{~ms} ; n=18$ ). This approach, which assumes that the release time course does not change across $\left[\mathrm{Ca}^{2+}\right]$ values (confirmed in Results; see Fig. 8), gave similar results to those obtained by subtracting the spillover waveform from the average EPSC at $2 \mathrm{~mm}\left[\mathrm{Ca}^{2+}\right]$ (paired $t$ test, $p=0.32$ ). Spillover data were judged to be reliable if (1) there were at least five isolated spillover responses, (2) the amplitude of the current at the peak of the direct response was more than three times the SD of the noise, and (3) the spillover current was not adversely influenced by the presence of the stimulus artifact. Spillover correction for MPFA was done using one of three approaches. If reliable spillover data were available at each $\left[\mathrm{Ca}^{2+}\right]$, then the mean and variance of the spillover at each $\left[\mathrm{Ca}^{2+}\right]$ was subtracted from the total. For those experimental conditions in which there was no reliable spillover data, we used one of two methods based on the mean relationships between the amplitude (and variance) of the spillover current and the EPSC amplitude at the time of peak of the direct response [estimated from the population and normalized to $2 \mathrm{~mm}\left[\mathrm{Ca}^{2+}\right]$ (see Fig. 3D1,D2)]. When reliable spillover data were available for at least one $\left[\mathrm{Ca}^{2+}\right]$ run $(12$ of 25 cells), they were used to scale the population current and variance curves to predict the contribution of spillover current and variance at the different $\left[\mathrm{Ca}^{2+}\right] \mathrm{s}$ used. If no isolated spillover data were available (11 of 25 cells), we estimated the amount of spillover at the peak of the direct response by using the average spillover waveform at $2 \mathrm{~mm}\left[\mathrm{Ca}^{2+}\right]$ from cells in which there was reliable spillover data $(n=26$ cells; this sample includes cells not used for MPFA). Because the average isolated spillover current was $84 \%$ of the mean EPSC $8 \mathrm{~ms}$ after its $10 \%$ rise, we estimated the spillover current by scaling the averaged spillover current waveform to the mean EPSC at this time point using this factor. The spillover at the peak of the direct response was then used to scale the population relationships (see Fig. 3D), which allowed spillover current and variance to be predicted at the other $\left[\mathrm{Ca}^{2+}\right]$ values. For simulations, the mean spillover current and the peak amplitude of individual spillover currents were determined for a connection by fitting Equation 1, which reduced the effects of background noise. The CV of the spillover current amplitude distribution was measured at the time of the peak of the spillover current.

Time course of vesicular release. The time course of vesicular release was determined either directly, by measuring the latencies of uniquantal events, or indirectly, by deconvolution. EPSC latency was determined from the time at which the fit of Equation 1 to individual quantal responses reached $20 \%$ of its peak. For connections with a single release site, the shape of the latency distribution is equal to the time course of the vesicular release function. The cumulative latency functions were divided by the total number of stimuli to give a final value of $(1-f)$, which is equal to $P_{\mathrm{R}}$ if $N=1$. To perform deconvolution, we used an algorithm implemented in Igor PRO that uses a Fourier transform method (Press et al., 1994). The quantal waveform (impulse response function) was determined for each cell from the spillover-corrected successes in low $\left[\mathrm{Ca}^{2+}\right]$ in which $f>0.7$. Accurate alignment was achieved by fitting each response to Equation 1 and aligning on their $20 \%$ rise. The waveform was scaled to correct for the presence of multiquantal events ( $0-15 \%$ scaling) (Silver, 2003, his Eq. 30). We also used Equation 1 to fit the average EPSC to eliminate background noise before performing deconvolution. Spillover correction was achieved by subtracting the fit of the average isolated spillover response from the fit of the averaged EPSC.

Simulations of EPSCs and EPSPs. Monte Carlo synaptic simulations were written in Igor PRO. EPSCs from an MF-GC connection were simulated using the mean quantal waveform (fitted using Eq. 1), integer $N$, $P_{\mathrm{R}}$, the spillover waveform, and the amplitude distribution of spillover, all of which were measured from individual connections. Stochastic release at each site was modeled by sampling from a uniform random distribution. The correct release probability was achieved at each release site by generating a quantal event on those trials when the random variable was less than or equal to $P_{\mathrm{R}}$. Quantal variability was included by allocating a mean quantal size to each site such that the mean quantal size of the connection was equal to $Q$, and their $\mathrm{CV}$ was equal to $\mathrm{CV}_{\mathrm{QII}}$. Intrasite quantal amplitude fluctuations were implemented by sampling from a Gaussian distribution with a $\mathrm{CV}=\mathrm{CV}_{\mathrm{QI}}$. The direct EPSC waveform was then generated by summing the different quantal events, each of which started at a time determined by random sampling from the mean vesicular release distribution at $2 \mathrm{~mm}\left[\mathrm{Ca}^{2+}\right]$. Spillover currents were generated by scaling the mean spillover waveform for a particular connection to a value randomly sampled from the amplitude distribution. The quantal current component and the spillover current were then summed on each trial to produce the combined EPSC. EPSPs were simulated using a single compartment conductance-based integrate-andfire model of a granule cell. The model had a leak conductance of $1 \mathrm{nS}$ with a reversal potential of $-80 \mathrm{mV}$, similar to the measured resting potential (Cathala et al., 2003), a capacitance of $2.5 \mathrm{pF}$, and a spike threshold of $-50 \mathrm{mV}$ (Mitchell and Silver, 2003). For comparisons of real and simulated EPSCs, we added Gaussian noise that had an SD similar to that recorded for that connection. Simulated EPSCs were converted to conductances, taking account of the $+6 \mathrm{mV}$ junction potential in the recording potential, and added to the integrate-and-fire model as a conductance with a reversal potential of $0 \mathrm{mV}$. The resulting voltage was calculated using the Euler numerical integration method (Press et al., 1994). The baseline voltage was adjusted by adding constant excitatory conductance with a reversal potential of $0 \mathrm{mV}$ to mimic depolarizing excitatory input.

\section{Results}

Variability in EPSC amplitude and shape arising from trialto-trial fluctuations at an individual mossy fiber-granule cell connection

EPSCs arising from single MF inputs were recorded at physiological temperature from GCs in acute cerebellar slices from postnatal day 25 rats (see Materials and Methods). We focused on the AMPAR-mediated components because the NMDA receptor component contributes little to low-frequency EPSCs at this age (Cathala et al., 2000). The shape and amplitude of AMPAR EPSCs varied from trial to trial, with two obvious components: a highly variable, fast-rising quantal current arising from glutamate released at synaptic contacts made directly onto the GC (direct release) and a more reliable, slow-rising current component mediated by spillover of transmitter from synapses connected to neighboring granule cells (Fig. 1 A1) (DiGregorio et al., 2002; Nielsen et al., 2004). Figure 1, A1 and A2, shows currents recorded from one MF connection, and Figure $1 B 1$ shows the 
EPSC amplitude distribution, which had a coefficient of variation of 0.74 , similar to the mean for 24 cells $(0.81 \pm 0.42)$, and exhibited no obvious multiquantal peaks. The relative variability in EPSC shape is illustrated in Figure 1B2, which shows the distribution of the weighted decay time constants of individual EPSCs (see Materials and Methods). The $\mathrm{CV}$ of the weighted decay for this cell was 0.61 , and the mean CV across 24 cells was $0.54 \pm$ 0.15 . The variability in the charge transfer (EPSC integral), which is determined by both the amplitude and decay time course, was also sizeable (0.30) (Fig. 1 B3). Across 24 cells, the CV for EPSC integral was $0.46 \pm 0.38$. It is clear from these measurements that considerable trial-to-trial variability in EPSC amplitude and shape occurs at a single MF-GC connection.

\section{Variability in EPSC amplitude and shape across connections}

The mean EPSC waveform measured from different MFs also exhibited considerable variability (DiGregorio et al., 2002). The population average EPSC amplitude across all connections was $-48 \mathrm{pA}$, but mean EPSCs for individual fibers ranged from -4 to $-159 \mathrm{pA}$. Figure $1 C$ shows the amplitude distribution of mean EPSCs for 79 different MF connections, which was skewed toward larger values. These results show that MF connections onto GCs have a wide range of synaptic amplitudes. The shape of mean EPSCs also varied from input to input with a $\mathrm{CV}$ of the weighted decay of 0.44 (Fig. $1 D$ ). Finally, the distribution of the charge transfer across fibers (Fig. 1E) was broad and had a CV (0.46) comparable with that observed for trialto-trial fluctuation at individual connections. In the following sections, we examine the quantal determinants of the mean and variability of EPSC amplitude and shape at individual fibers and use a quantal model of synaptic transmission to investigate the effect of the underlying stochastic processes on synaptic integration in GCs.

\section{Properties of quantal and spillover currents at connections} with a putative single release site

To investigate the quantal properties of transmission at synapses onto GCs, it was necessary to separate currents mediated by direct quantal release and spillover, which we have shown previously contributes $11 \%$ of the current at the peak of the EPSC on average (Fig. 1A2) (see Materials and Methods) (DiGregorio et al., 2002). We took advantage of the fact that a subset of MF-GC synapses have a single functional release site (Silver et al., 1996b; Wall and Usowicz, 1998) to examine the properties of release and determine how quantal- and spillover-mediated current components interact. Figure $2 \mathrm{~A}$ shows AMPAR-mediated EPSCs from a putative single-site MF input recorded in three different extracellular $\left[\mathrm{Ca}^{2+}\right]$ values. At $1.25 \mathrm{~mm}\left[\mathrm{Ca}^{2+}\right]$, the fraction of fast-rising EPSC successes was 0.13 , and the failures showed little evidence different MF-GC connections.
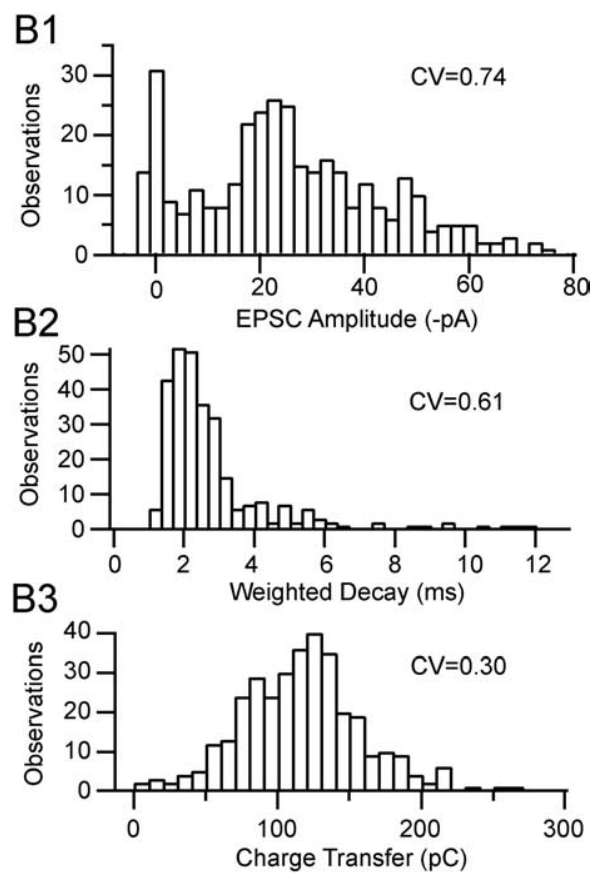

E

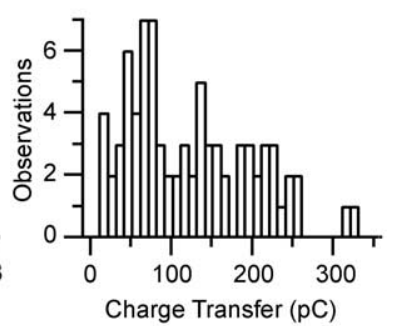

Figure 1. MF-GCEPSCs display considerable variability in amplitude and shape from trial to trial at an individual connection and across connections. A1, Five consecutive EPSCs arising from an individual MF-GC connection (artifact blanked). A2, Fifty superimamplitude. $\boldsymbol{C}-\boldsymbol{E}$ show distributions of peak amplitude $(\boldsymbol{C})$, weighted decay $(\boldsymbol{D})$, and charge transfer $(\boldsymbol{E})$ of the mean EPSCs across 79

of a slow-rising spillover current component. At 2 and $5 \mathrm{~mm}$ $\left[\mathrm{Ca}^{2+}\right]$, the proportion of these fast-rising EPSC successes increased (to 0.22 and 0.77 , respectively), whereas the failures exhibited a robust spillover current component. If this connection had two identical release sites, then the decrease in failure rate observed between 1.25 and $5 \mathrm{~mm}\left[\mathrm{Ca}^{2+}\right]$ should have been accompanied by an increase in the amplitude of the EPSC successes from $-15.9 \mathrm{pA}$, close to the quantal size, to $-20.8 \mathrm{pA}$ (for details, see legend of Fig. 2 B). However, the local EPSC successes, including spillover, increased only to $-17.6 \mathrm{pA}$ (Fig. $2 \mathrm{~B}$, black trace), which is significantly smaller than the amplitude expected for the two-site case assuming the same SD (unpaired $t$ test, $p<$ $0.00001)$. Moreover, if we correct for the spillover component (Fig. $2 \mathrm{~B}$, green trace), by assuming that the spillover current and the local current sum linearly at the peak of the direct response, the mean amplitudes of the EPSC successes was independent of $\left[\mathrm{Ca}^{2+}\right]$ (Fig. $2 B$, red trace) $(r=0.44 ; p=0.71)$ and success rate $(1-f ; r=0.40 ; p=0.74)$. This indicates that quantal transmission is all-or-none and that the connection had a single functional release site (Stevens and Wang, 1995; Silver et al., 1996b). 

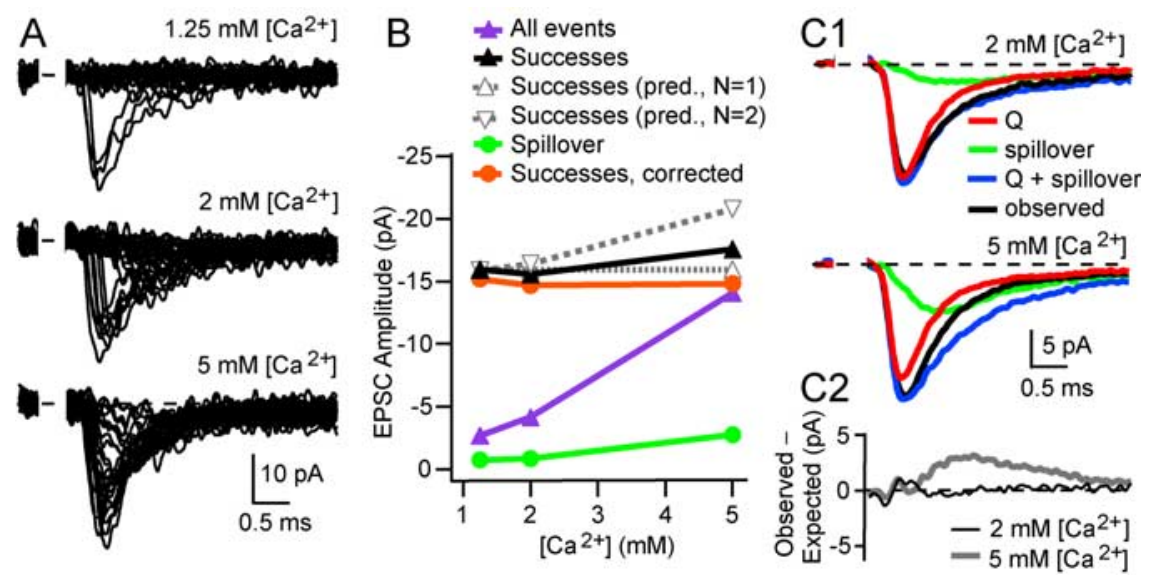

Figure 2. Analysis of an MF-GC connection with a putative single functional release site. $\boldsymbol{A}$ shows three sets of 25 consecutive responses at $1.25,2$, and $5 \mathrm{~mm}\left[\mathrm{Ca}^{2+}\right]$; stimulus artifacts have been blanked. $\boldsymbol{B}$, Relationship between the mean amplitude of all responses (purple), successes (black), spillover-corrected successes (red), isolated spillover (green), and $\left[\mathrm{Ca}^{2+}\right]$. Open triangles indicate the predicted relationship between mean amplitude of EPSC successes $(\boldsymbol{A})$ and $\left[\mathrm{Ca}^{2+}\right]$ assuming $N=1$ (tip up) or $N=2$ (tip down) from the following:

$$
A=N Q \frac{\left(1-f^{1 / N}\right)}{(1-f)},
$$

where the failure rate $(f)=0.87,0.78$, and 0.23 at 1,2 , and $5 \mathrm{~mm}\left[\mathrm{Ca}^{2+}\right]$, respectively. $\mathrm{C}$ shows isolated components of the EPSC and their sum in $2 \mathrm{~mm}\left[\mathrm{Ca}^{2+}\right]$ (top) and $5 \mathrm{~mm}\left[\mathrm{Ca}^{2+}\right]$ (bottom). The red traces show the quantal waveform measured at $1.25 \mathrm{~mm}$ $\left[\mathrm{Ca}^{2+}\right]$. The green traces show the mean isolated spillover current in the absence of direct release. The blue traces show the linear sum of the spillover and quantal currents, and the black traces show the observed mean successes. $\mathbf{2}$ shows the difference between observed and expected current waveforms in $\mathbf{C 1}$.

We identified one other connection with a single release site in the sample of $25 \mathrm{MF}-\mathrm{GC}$ synapses.

By subtracting spillover current from total current, we are assuming that AMPARs are operating in the linear range of their dose-response curve. To examine whether this assumption is justified, we compared the linear sum (Fig. 2C1, blue trace) of the isolated direct release component recorded in $1.25 \mathrm{~mm}\left[\mathrm{Ca}^{2+}\right]$ (red), in which spillover is minimal, and the isolated spillover current at elevated $\left[\mathrm{Ca}^{2+}\right]$ (green) with the mean of EPSC successes at the elevated $\left[\mathrm{Ca}^{2+}\right]$ (black). The mean of the EPSC successes and the sum of the isolated local release and spillover current components were comparable at the peak of the EPSC in both 2 and $5 \mathrm{~mm}\left[\mathrm{Ca}^{2+}\right]$. Figure $2 \mathrm{C} 2$ shows the difference between the expected and observed currents. At early times, the difference was close to zero, as expected for linear summation, but increased after the time of the peak for $5 \mathrm{~mm}\left[\mathrm{Ca}^{2+}\right]$, suggesting that receptor desensitization occurs at higher release probabilities. Application of cyclothiazide $(25-50 \mu \mathrm{M})$ and kynurenic acid (1.5-3 mM), to reduce desensitization and lower the apparent affinity of the AMPA receptor (EPSC amplitude, $48 \pm 5 \%$ of control) increased the weighted decay of EPSCs measured in 8 $\mathrm{mm}\left[\mathrm{Ca}^{2+}\right]$ by twofold at multisite connections $(2.08 \pm 0.11 ; p<$ 0.001 by paired $t$ test; $n=7$ ), consistent with the presence of desensitization. Across the two single-site cells, the mean ratio of the observed and predicted currents summation was $109 \%$ in 2 $\mathrm{mm}\left[\mathrm{Ca}^{2+}\right]$, consistent with linear summation. These observations reinforce our previous studies at this synapse showing that AMPARs are not saturated by a quantum of transmitter (Silver et al., 1996b; Nielsen et al., 2004). The intermediate receptor occupancy and the all-or-none behavior of single-site synapses suggest that transmission is mediated by the release of a single quantum, which is likely to correspond to a single vesicle (Sun et al., 2002).
Quantal properties within and across release sites

Previous studies have established that quantal size varies from trial to trial at individual release sites (intrasite or type I quantal variance) (Silver et al., 1996b; Forti et al., 1997; Bekkers and Clements, 1999; Liu et al., 1999); this variability could arise from a variation in vesicular content (Frerking et al., 1995), variation in vesicle diameter (10\% CV in vesicle diameter) (Palay and Chan-Palay, 1974), and stochastic channel gating (Faber et al., 1992; Traynelis et al., 1993; Silver et al., 1996b). Variability also arises from differences in the mean quantal size across sites (intersite or type II quantal variance) (Bekkers et al., 1990; Borst et al., 1994; Frerking and Wilson, 1999), which reflects differences in the mean number of channels activated. Because these types of quantal variability are likely to influence the stochastic properties of EPSCs in different ways (Silver, 2003), we investigated the origins of quantal variability at the MF-GC synapse. We first examined the properties of quantal EPSCs arising from MF connections with multiple release sites by lowering release probability to a level at which the vast majority of EPSCs are composed of single quanta (1-1.25 mM $\left[\mathrm{Ca}^{2+}\right]$; failure rate, $0.88 \pm 0.03 ; n=5$ ) (Silver, 2003). Risealigned uniquantal EPSCs had fast kinetics with a $10-90 \%$ rise time of $111 \pm 24 \mu \mathrm{s}$, a mean amplitude $(Q)$ of $-18.4 \pm 2.3 \mathrm{pA}$, and a biexponential decay time course, with a rapid phase of decay of $0.30 \pm 0.05 \mathrm{~ms}(77 \pm 5 \%$ of the total $)$ and a slow phase of decay of $2.2 \pm 0.5 \mathrm{~ms}$. These properties are similar to miniature EPSCs (Cathala et al., 2003). The total quantal variability (defined in terms of coefficient of variation) at the peak of the stimulus-aligned quantal EPSC $\left(\mathrm{CV}_{\mathrm{QT}}=0.49 ; n=14\right)$ arises from three sources: 1) trial-to-trial variability in the amplitude of quantal EPSCs at an individual site, 2) trial-to-trial variability in the amplitude of the quantal current at the time of the peak of the mean EPSC attributable to asynchrony in quantal release, and 3) differences in the mean quantal size across release sites $\left(\mathrm{CV}_{\mathrm{QII}}\right)$. Our estimates (see Materials and Methods) suggest that variability arising from amplitude fluctuations and release jitter at individual release sites $\left(\mathrm{CV}_{\mathrm{QI}}=0.38\right)$ is comparable with variability arising from differences in quantal size across release sites $\left(\mathrm{CV}_{\mathrm{QII}}=0.31\right)$.

\section{Estimation of quantal parameters with MPFA}

To quantify the stochastic properties of transmission at MF connections with more than one release site, we estimated the mean quantal parameters with MPFA (Silver et al., 1998, 2003; Silver, 2003), also known as variance-mean analysis (Reid and Clements, 1999; Clements and Silver, 2000). To do this, we needed to correct for the mean and variance arising from the spillover current component. Figure $3 A$ shows individual EPSCs (black traces) and the mean spillover current (gray trace) recorded in 2 $\mathrm{mm}\left[\mathrm{Ca}^{2+}\right]$. EPSC peak amplitude and baseline current measurements were calculated for each trial during application of four different $\left[\mathrm{Ca}^{2+}\right] /\left[\mathrm{Mg}^{2+}\right]$ solutions, which imposed different probabilities of release (Fig. $3 B$ ) (see Materials and Methods). We 
then calculated the mean and baseline noise-corrected variance at the peak of the EPSC from all time-stable EPSCs in a particular condition. Figure $3 C$ illustrates mean EPSCs (black) and isolated spillover currents (gray) recorded in the various $\left[\mathrm{Ca}^{2+}\right] /\left[\mathrm{Mg}^{2+}\right]$ solutions. Because there were usually no isolated spillover currents at high probabilities of release, as a result of a lack of failures of the local component, we developed methods for estimating the mean and variance of spillover from the population behavior. For all experiments in which there was sufficient spillover data available (see Materials and Methods), we plotted the mean fractional current and the fractional variance arising from spillover at the time of the peak of the direct component of the EPSC as a function of the normalized current (Fig. 3D). These population relationships were then scaled for each cell (Materials and Methods) and used to predict the mean current and variance produced by the spillover current. Figure $3 E$ shows the variance-mean relationship in the presence of spillover currents (filled triangles, black line) and the relationship after correction for spillover in this cell (open triangles, gray line). Weighted fits of Equation 2 to the variance-mean relationships gave estimates for the mean quantal size at the time of the peak of the stimulus-aligned EPSC $\left(Q_{P}\right)$, the number of functional sites that generate a quantal event $(N)$, and the mean release probability at each site $\left(P_{\mathrm{R}}\right)$. For this cell, these were $Q_{\mathrm{P}}=$ $-14.5 \mathrm{pA}, N=6.8$, and $P_{\mathrm{R}}(2 \mathrm{~mm}$ $\left.\left[\mathrm{Ca}^{2+}\right]\right)=0.58$ for the uncorrected plot, and $Q_{\mathrm{P}}=-16.3 \mathrm{pA}, N=5.2$, and $P_{\mathrm{R}}(2$ $\left.\mathrm{mm}\left[\mathrm{Ca}^{2+}\right]\right)=0.60$ for the spillovercorrected plot. On average, spillover correction increased $Q_{\mathrm{P}}$ by $20 \pm 18 \%$ and reduced $N$ by $28 \pm 17 \%(p<0.001$ by paired $t$ tests; $n=25$ ) (Fig. $3 F$ ).

Across $25 \mathrm{MF}$ connections, the mean amplitude of $Q_{P}$ estimated with spillovercorrected MPFA, $-15.5 \pm 5.1 \mathrm{pA}$, was not significantly different from $Q_{\mathrm{P}}$ measured directly from stimulus-aligned uniquantal EP-

SCs recorded under low probability conditions $\left(Q_{P} ;-15.8 \pm 2.5\right.$ $\mathrm{pA} ; p=0.91)$. The spillover-corrected value of $N$ was $4.7 \pm 2.6(n=$ 25), which is within the range of three to six postsynaptic densities (PSDs) present per GC dendrite in the rat (Jakab and Hamori, 1988) and is comparable with the mean number of six anatomical PSDs per GC dendrite, calculated from the mean number of PSDs (330) (XuFriedman and Regehr, 2003) and the mean number of GCs (53 per MF terminal) (Jakab and Hamori, 1988), taking into account developmental changes (Hamori and Somogyi, 1983). The mean $P_{\mathrm{R}}$ in 2 $\mathrm{mm}\left[\mathrm{Ca}^{2+}\right]$ was $0.48 \pm 0.22(n=25)$, but the maximal release probability observed under high $\left[\mathrm{Ca}^{2+}\right]$ conditions was close to unity $\left(P_{\mathrm{R}}=0.81 \pm 0.17\right.$ at $5 \mathrm{mM}\left[\mathrm{Ca}^{2+}\right], n=8 ; P_{\mathrm{R}}=0.97 \pm 0.12$ at $\left.8 \mathrm{~mm}\left[\mathrm{Ca}^{2+}\right], n=17\right)$.

A

C
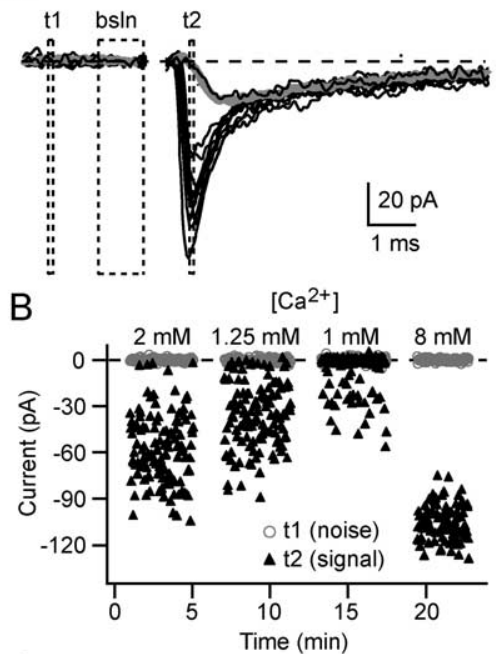

Figure 3. Correction for spillover increases the estimated quantal size and decreases the estimated number of release sites at MF-GC synaptic connections. A, Black traces show 10 superimposed consecutive EPSCs collected in $2 \mathrm{~mm}\left[\mathrm{Ca}^{2+}\right.$ ] (artifact blanked). baseline the currents, and $\mathrm{t} 1$ and $\mathrm{t} 2$ show the measurement windows $(0.1 \mathrm{~ms})$ for baseline noise and peak amplitude (at the peak 列 . response as a function of the mean EPSC normalized to $2 \mathrm{~mm}\left[\mathrm{Ca}^{2+}\right]$. Measurements were grouped by $\left[\mathrm{Ca}^{2+}\right]$ (in mM): 1, 1.25, 1.5, 2, and 3-8. The smooth curves in $\boldsymbol{D}$ are fits: $y=0.12 x^{0.4}(\mathbf{D 1})$ and $y=0.02 x$ (D2). Each data point is the average of $10-29$ values, for uncorrected and spillover-corrected data. $F$ shows estimates for the uncorrected and spillover-corrected quantal parameters $Q_{p}$ and $N$ for 25 MF-GC connections.

\section{Interpretation of $N$ and $P_{\mathrm{R}}$ at synaptic connections with} multiple release sites

The interpretation of $N$, determined with MPFA, depends on the properties of release at an individual synaptic contact (Silver, 2003). Although the properties of single-site connections suggest that transmission at an individual synaptic contact can be mediated by the all-or-none release of a single vesicle (univesicular release), this is not necessarily the case at connections with multiple release sites. Indeed, if multiple vesicles are released per synaptic contact per AP [multivesicular release (Wadiche and Jahr, 2001; Oertner et al., 2002)] and if receptor saturation occurs (Foster et al., 2002; Harrison and Jahr, 2003), $N$ would correspond to the number of PSDs at which one or more vesicles were 

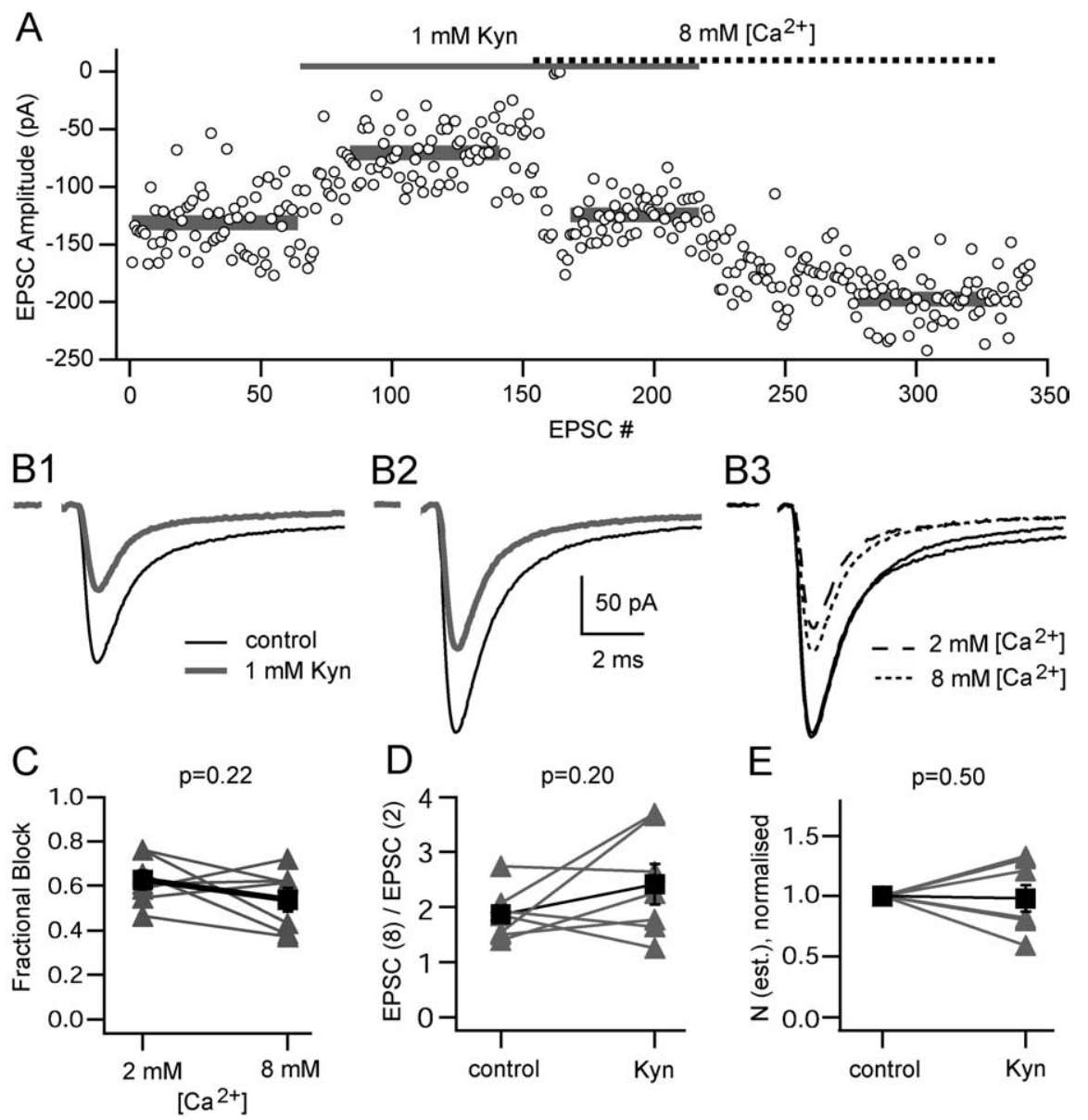

Figure 4. Fractional block of the EPSC by the rapidly dissociating antagonists kynurenic acid is similar at 2 and $8 \mathrm{~mm}\left[\mathrm{Ca}^{2+}\right]$, suggesting that peak [glutamate] is independent of release probability. $A$ shows the EPSC peak amplitude during an experiment in which $1 \mathrm{~mm}$ Kyn was added to the external solution (thin gray bar) and the $\left[\mathrm{Ca}^{2+}\right]$ was changed from 2 to $8 \mathrm{~mm}$ (dashed bar). $\boldsymbol{B} 1$ and $\boldsymbol{B} 2$ show average EPSC size from the four stable epochs indicated by the thick gray bars in $\boldsymbol{A}$ (artifact blanked). $\boldsymbol{B} 1$ shows data in $2 \mathrm{~mm}\left[\mathrm{Ca}^{2+}\right]$ and $\boldsymbol{B} 2$ in $8 \mathrm{~mm}\left[\mathrm{Ca}^{2+}\right] . \boldsymbol{B} 3$ plots records from $\boldsymbol{B} 1$ and $\boldsymbol{B} \boldsymbol{2}$ normalized to the control peak response. $\boldsymbol{C}$ shows the fractional block of the EPSC by $1 \mathrm{~mm}$ Kyn in 2 and $8 \mathrm{~mm}\left[\mathrm{Ca}^{2+}\right]$ across cells. D shows the fractional change in the EPSC amplitude between 2 and $8 \mathrm{~mm}\left[\mathrm{Ca}^{2+}\right]$ in control and $1 \mathrm{~mm}$ Kyn. $E$ plots the number of functional release sites $\left(N_{\text {est }}\right)$, normalized to control conditions, for control and $1 \mathrm{~mm}$ Kyn. $N_{\text {est }}$ was estimated from the ratio of the mean amplitude of the EPSC at $8 \mathrm{~mm}\left[\mathrm{Ca}^{2+}\right]$ and the variance/mean of EPSCs recorded in $1.25 \mathrm{~mm}\left[\mathrm{Ca}^{2+}\right]$, in control conditions or in Kyn. Because release probability at $8 \mathrm{~mm}\left[\mathrm{Ca}^{2+}\right]$ is $\approx 1$ (see Results), this gives an estimate of $N$.

released rather than the number of vesicles released (Silver, 2003). Under these conditions, $P_{\mathrm{R}}$ would correspond to the mean probability that transmitter was released at a synaptic contact rather than the vesicular release probability. Moreover, if multivesicular release and saturation occur, then the number of functional release sites would be expected to increase as the receptor occupancy is lowered by competitive antagonists (Foster and Regehr, 2004). We investigated whether quanta summate linearly over the range of release probabilities at the MF-GC synapse by examining the fractional block of the EPSC amplitude by the rapidly equilibrating competitive AMPAR antagonist Kyn in different external $\left[\mathrm{Ca}^{2+}\right]$ values. Figure $4 A$ shows the effect of $1 \mathrm{~mm}$ kynurenic acid on individual EPSC amplitudes recorded in $2 \mathrm{~mm}$ $\left[\mathrm{Ca}^{2+}\right]$ and when release probability was maximized with $8 \mathrm{~mm}$ $\left[\mathrm{Ca}^{2+}\right]$. The fractional block of the mean EPSC by kynurenic acid was similar in 2 and $8 \mathrm{~mm}\left[\mathrm{Ca}^{2+}\right]$ in this cell (Fig. $4 \mathrm{B1}, \mathrm{B2}$ ), as can be seen from the normalized EPSC traces (Fig. 4B3). Across seven cells, the fractional block of the EPSC by kynurenic acid in $2 \mathrm{~mm}$ $\left[\mathrm{Ca}^{2+}\right]$ was not significantly different from that in $8 \mathrm{~mm}\left[\mathrm{Ca}^{2+}\right]$ $(63 \pm 4$ and $54 \pm 5 \%$, respectively; $p=0.22)$ (Fig. $4 C$ ). Alterna- tively, if we compare the relative increase in the mean EPSC from 2 to $8 \mathrm{~mm}\left[\mathrm{Ca}^{2+}\right]$, under control conditions and when receptor occupancy is lowered with kynurenic acid, we did not detect a difference (control, $1.9 \pm 0.5 ; \mathrm{Kyn}, 2.4 \pm 1.0 ; p=0.2 ; n=$ 7) (Fig. $4 D$ ), suggesting that quanta summate linearly. We further tested this by examining whether $N$ depended on receptor occupancy. We compared the estimate of $N$, obtained from the quantal content when release was maximal $\left(8 \mathrm{~mm}\left[\mathrm{Ca}^{2+}\right]\right.$; in which $N P_{\mathrm{R}} \sim N$ ), in the presence and absence of $1 \mathrm{~mm}$ kynurenic acid by dividing the mean currents by their respective quantal sizes (control, $-10.6 \pm 1.7 \mathrm{pA}$; Kyn, $-5.0 \pm 0.7 \mathrm{pA} ; n=7$, measured from the variance/mean at $1.25 \mathrm{~mm}$ $\left.\left[\mathrm{Ca}^{2+}\right]\right)$. The estimate of $N$ was unchanged in the presence of kynurenic acid (ratio of Kyn to control, $0.98 \pm 0.11 ; n=$ $7 ; p=0.50$ ) (Fig. $4 E$ ), which shows that no new release sites were revealed by lowering receptor occupancy. These results indicate that quanta summate linearly over the entire range of $P_{\mathrm{R}}$.

The lack of a differential effect of kynurenic acid is not attributable to lack of equilibration during the rising phase of the EPSC, because the fractional block of the current increases after the peak of the EPSC (DiGregorio et al., 2002), indicating that the fraction of AMPA receptors bound by kynurenic acid falls significantly from its maximal preequilibrated level during the rising phase of the EPSC. It has been shown previously that a competitive antagonist approach can distinguish the large glutamate concentration differences that occur when release probability is increased at synaptic contacts in which up to four vesicles are released (Wadiche and Jahr, 2001), but it may not be able to resolve the smaller differences in glutamate concentration arising from synaptic contacts if only two vesicular release sites are present. It is difficult to quantify the minimum concentration change this method can resolve without a detailed kinetic scheme for the synaptic receptor that included kynurenic acid binding. Nevertheless, our results do show that released quanta summate linearly at the peak of the EPSC. This suggests that that release is either univesicular or that receptor occupancy is sufficiently low during a quantal event that multiple quanta summate linearly at a single synaptic contact. Because quanta summate linearly at the MF-GC synapse, interpretation of quantal parameters estimated with MPFA is straightforward (Silver, 2003): $N$ is the number of vesicular release sites (but not necessarily PSDs), $P_{\mathrm{R}}$ is the mean probability that a vesicle is released at an individual release site, and $Q$ is the amplitude of the postsynaptic response to the release of a vesicle.

\section{Heterogeneity in the EPSC amplitude across fibers arises} from differences in $N, P_{\mathrm{R}}$, and $Q_{\mathrm{P}}$

Quantal parameters underlying transmission varied widely across $\mathrm{MF}$ inputs, with $Q_{\mathrm{P}}$ ranging from -6.1 to $-31.5 \mathrm{pA}(\mathrm{CV}=$ 
0.33 ) (Fig. $5 A-C$ ), $N$ varying from 0.9 to $11.2(\mathrm{CV}=0.56)($ Fig. $5 A, B)$, and $P_{\mathrm{R}}$ at 2 $\mathrm{mM}\left[\mathrm{Ca}^{2+}\right]$ varying from 0.17 to 0.87 $(\mathrm{CV}=0.46)$ (Fig. 5C). However, these quantal parameters were not correlated with one another (Fig. $5 A-C$ ). The independent variation in each of the quantal properties of MF-GC connections combine to produce a 30 -fold range in the direct quantal component of the EPSC across fibers $(-3.1$ to $-94.0 \mathrm{pA})$. To investigate the mechanisms of synaptic strength further, we examined whether the release probability at the 200-400 release sites (Xu-Friedman and Regehr, 2003) connected to the 50 GCs on a particular MF terminal (Jakab and Hamori, 1988 ) is correlated. Because the spillover current increases when release probability is raised by increasing external $\left[\mathrm{Ca}^{2+}\right]$ (DiGregorio et al., 2002) and because it reflects the behavior of many surrounding release sites (Nielsen et al., 2004), it can be used as an assay of the mean $P_{\mathrm{R}}$ across the release sites connected to other GCs at a particular $\mathrm{MF}$ terminal. If $P_{\mathrm{R}}$ at release sites connected to a particular GC reflects the mean $P_{\mathrm{R}}$ of sites over the whole terminal, then $P_{\mathrm{R}}$ and spillover should be correlated across MF connections when variability arising from different $N$ and $Q_{P}$ is accounted for. Figure $5 D$ shows the relationship between $P_{\mathrm{R}}$ and the peak spillover current normalized by $N Q_{\mathrm{P}}$, the maximal postsynaptic response. The significant positive correlation across MFs in $2 \mathrm{mM}\left[\mathrm{Ca}^{2+}\right]$ suggests that the $P_{\mathrm{R}}$ of local and neighboring release sites is correlated. We also examined the uniformity in $P_{\mathrm{R}}$ at individual MF-GC synapses by applying a multinomial quantal model that included non-uniform release probability (Eq. 3) (Silver, 2003). In cells in which it was possible to apply the non-uniform release probability model (see Materials and Methods), we estimated the $\mathrm{CV}$ of $P_{\mathrm{R}}$ across sites from the fit parameter $\alpha$ and Equation 4 (Silver, 2003). The mean CV of $P_{\mathrm{R}}$ across sites was $0.14(n=7)$, indicating that $P_{\mathrm{R}}$ is relatively uniform across sites at individual MF connections. These results suggest that the release sites onto the 50 or so GCs connected to a particular MF rosette have similar $P_{\mathrm{R}}$ values.

Time course of vesicular release probability at single sites Because MPFA only gives a "snapshot" of $P_{\mathrm{R}}$ at the time of the peak of the EPSC, we investigated the time course over which vesicles are released, because this synaptic parameter may impose a fundamental limit on the temporal precision of synaptic signaling. At single-site MF connections, in which each EPSC corresponds to the release of a single vesicle, the time course of vesicular release can be measured directly from the timing of individual EPSCs. To minimize errors introduced by noise, we assessed the times at which release occurred from the $20 \%$ rise of fits of Equation 1 to individual EPSCs (see Materials and Methods). Figure $6 \mathrm{~A}$ shows fits of Equation 1 to individual quantal EPSCs recorded from a single-site connection at high temporal resolution. The EPSC latency histogram had a Gaussian shape with a slight skew, with the majority of release occurring within a
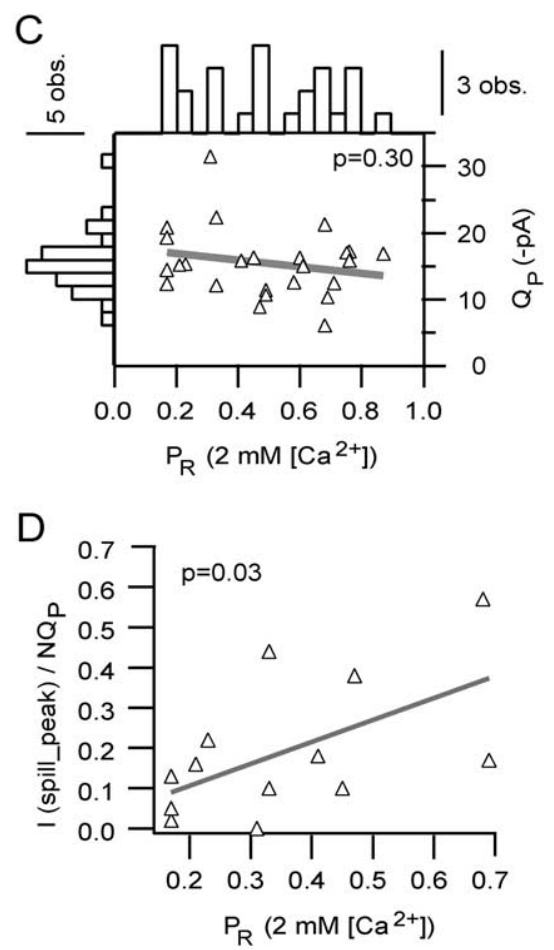

$\triangle$
$\Delta$
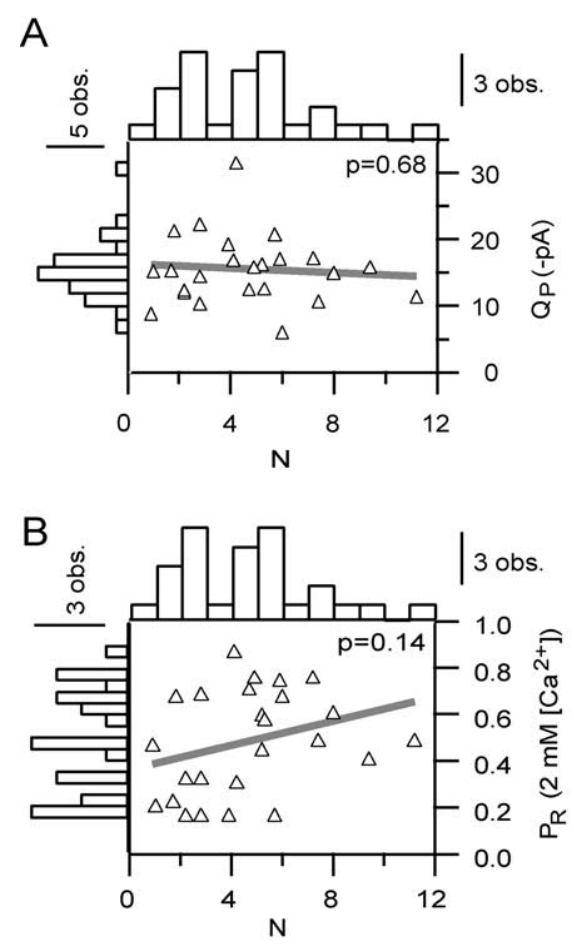

Figure 5. Quantal parameters vary independently across MF-GC synaptic connections. $\boldsymbol{A}$ shows the relationship between $Q_{P}$ N; $B$ shows the relationship between $P_{\mathrm{R}}$ at $2 \mathrm{~mm}\left[\mathrm{Ca}^{2+}\right]$ and $N$; and $\boldsymbol{C}$ shows the relationship between $Q_{P}$ and $P_{\mathrm{R}}$ at $2 \mathrm{~mm}$ current amplitude, I (spill_peak), normalized by $N Q_{p}$, is significantly correlated with $P_{R}$ across MF connections. Dividing the spillover current amplitude by $N Q_{p}$ accounts for cell-to-cell differences in the number of AMPARs that detect the spillover current.

$200 \mu$ s window. The fit to a Gaussian function had an SD of $70 \mu \mathrm{s}$ (Fig. $6 \mathrm{~B}$, green line) (382 responses in 500 trials; $5 \mathrm{~mm}\left[\mathrm{Ca}^{2+}\right]$ ). Because the time course of release is faster than the decay of the quantal EPSCs, the $0.1 \mathrm{~ms}$ peak of the stimulus-aligned mean EPSC waveform occurred near the end of the release function (Fig. 6B, magenta line segment). The value of $P_{\mathrm{R}}$, estimated at the peak of the mean EPSC with MPFA, therefore corresponds more closely to the final release probability than the probability at the peak of the release rate. The time course of the vesicular release probability, $P_{\mathrm{R}}(t)$, was calculated for different $\left[\mathrm{Ca}^{2+}\right]$ values by integrating the release function and dividing by the number of stimuli (Fig. 6C). The different $\left[\mathrm{Ca}^{2+}\right]$ solutions introduced slight temporal offsets in the cumulative release function. This is likely to be attributable to changes in fiber excitability, because there was no correlation across connections between the latency and $\left[\mathrm{Ca}^{2+}\right]$ (measured relative to $2 \mathrm{mM}\left[\mathrm{Ca}^{2+}\right] ; r=-0.09 ; p=$ 0.48 ). Comparison of the normalized cumulative release functions aligned on their $50 \%$ rise time indicates that there was no change in the shape of the vesicular release function $(p=0.62-$ 0.97 , three pairwise comparisons, Kolmogorov-Smirnov test) over a wide range of $P_{\mathrm{R}}$ values (Fig. 6D).

\section{Time course of vesicular release probability at multisite connections}

Measurement of $P_{\mathrm{R}}(t)$ directly from the EPSC latency is limited because it is only valid for single-site connections. Although this approach can be extended to connections with many release sites if a correction is made (Barrett and Stevens, 1972), it becomes inaccurate at intermediate and high $P_{\mathrm{R}}$ values when the fraction of failures becomes small. An alternative approach is to estimate 

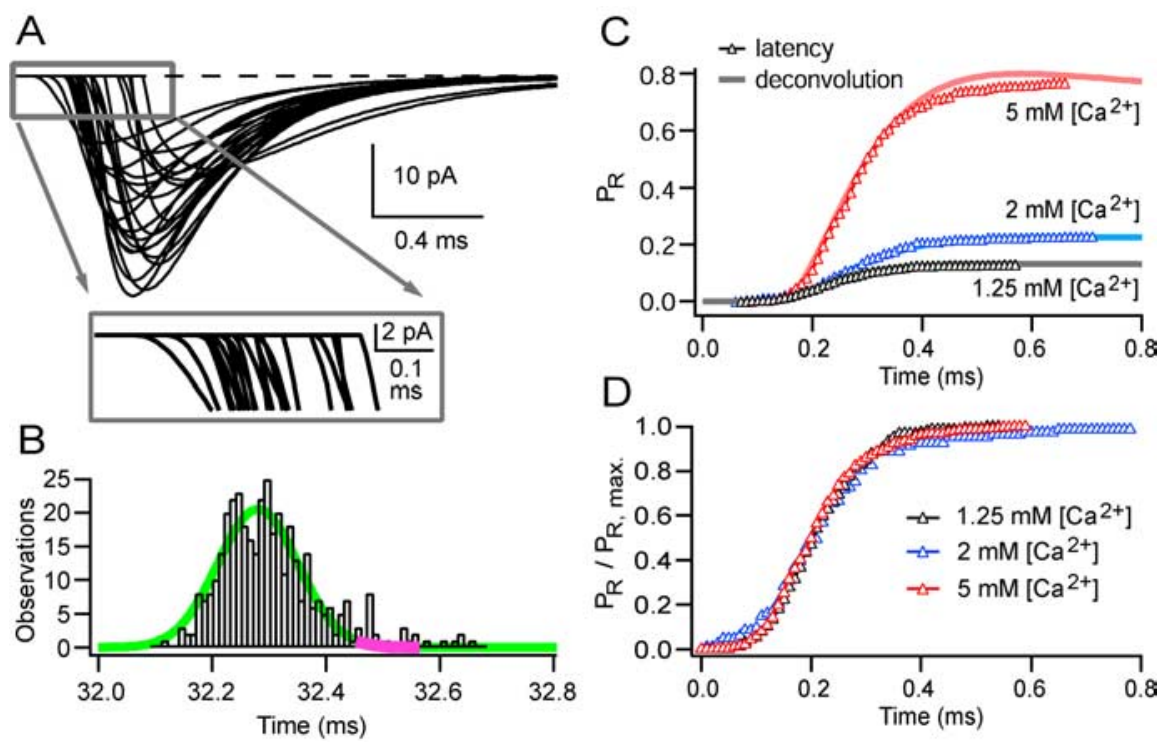

Figure 6. The time course of vesicular release at single-site MF- $\mathrm{GC}$ connections is similar at different $\left[\mathrm{Ca}^{2+}\right]$ values. $A, A$ total of 24 fits of consecutive EPSCs (Eq. 1) from a set of 382 successes recorded from a single-site synapse at $5 \mathrm{~mm}\left[\mathrm{Ca}^{2+}\right.$ ]. The inset shows an expanded view on the same time base as the distribution of all 382 latencies, shown in $\boldsymbol{B}$. EPSC latency was measured at the $20 \%$ rise time of the fits. The smooth green line shows a Gaussian fit with an SD of $70 \mu$ s; the magenta segment of this line shows the $0.1 \mathrm{~ms}$ window corresponding to the peak of the direct response. C shows cumulative release functions for three $\left[\mathrm{Ca}^{2+}\right]$ values (open triangles), calculated from the latency distribution and normalized by the number of stimuli. This gives $P_{\mathrm{R}}(t)$. The solid lines show the cumulative release functions calculated from the mean spillover-corrected waveform and the quantal waveform using deconvolution. $\boldsymbol{D}$ shows the data in $\mathbf{C}$ but normalized to the peak of the direct response; the distributions are similar ( $p=$ $0.69-0.91$ by pairwise Kolmogorov-Smirnov tests). The cumulative function derived from the $1.25 \mathrm{~mm}\left[\mathrm{Ca}^{2+}\right]$ run was moved $0.05 \mathrm{~ms}$ to right to align the curves to account for presumed differences in fiber excitability (see Results).

the release waveform from the mean EPSC waveform. If quantal events sum linearly, the mean EPSC waveform is the convolution of the quantal current waveform (impulse response in linear systems analysis) and the vesicular release time course. Under these conditions, deconvolution analysis (Cohen et al., 1981) can therefore be used to calculate the time course of quantal release from the mean EPSC and the quantal EPSC waveforms (Van der Kloot, 1988; Borst et al., 1995; Diamond and Jahr, 1995; Isaacson and Walmsley, 1995; Chen and Regehr, 1999; Schneggenburger and Neher, 2000) (but, for a nonlinear approach, see Neher and Sakaba, 2001). Before applying deconvolution to the multisite connections, we first tested whether it could be used to estimate reliably the time course of release under our experimental conditions. Figure $6 C$ shows that the cumulative release functions estimated with deconvolution closely match those measured directly from the EPSC latency distributions at a single-site synapse at different $P_{\mathrm{R}}$ values. Similar results were found for the second single-site connection, at which four $\left[\mathrm{Ca}^{2+}\right]$ s were used, and at four multisite connections in which the release probability was reduced to a level at which uniquantal events predominate [failures, $>0.85$; fraction of multiquantal events, $\sim 5 \%$ (based on Silver, 2003, his Eq. 30, assuming $N=5$ )]. In these cells, the cumulative latency function measured from EPSC latencies and from deconvolution was similar in 10 of 11 instances $(p=0.23-$ 0.96 by Kolmogorov-Smirnov test; the one difference is illustrated in Fig. $6 \mathrm{C}$ at $\left.5 \mathrm{~mm}\left[\mathrm{Ca}^{2+}\right]\right)$. This shows that deconvolution methods can be used to measure the vesicular release time course at the MF-GC synapse over a range of $P_{\mathrm{R}}$ values and confirms that quantal events and spillover currents sum linearly at early times.

We performed deconvolution analyses at multisite connections in which we had estimated quantal parameters with MPFA, because combining these methods allows calculation of the vesic- ular release time course, the peak release rate per site, and the final value of the vesicular release probability function. Because the deconvolution method is sensitive to noise, the mean quantal waveform was determined by fitting each quantal EPSC, evoked under low release probability conditions (Fig. $7 A$ ), with Equation 1 and aligning the fits on their $20 \%$ rise point (Fig. $7 B$ ). We also fit Equation 1 to the mean EPSC waveform and used the fitted function instead of the mean current for deconvolution (see Materials and Methods). Figure 7C shows the mean EPSC waveform (black), the spillover current component (gray), and the fit of the spillover-corrected waveform (dashed line) for the same connection in three different $\left[\mathrm{Ca}^{2+}\right]$ values. Deconvolution of the mean EPSC with the quantal event (see Materials and Methods) provided the vesicular release rate as a function of time across all release sites at the connection. Figure $7 D$ shows the vesicular release rate for this connection at $2 \mathrm{mM}\left[\mathrm{Ca}^{2+}\right]$ both with and without spillover correction. Although spillover had little effect on the release rate at early times, it introduced a tail (Fig. 7D, arrow) that was not seen for the spillover-corrected mean waveform or when the release waveform was calculated from the EPSC latency distribution at single sites (Fig. 6B). By integrating the spillover-corrected vesicular release functions and dividing by $N$, it was possible to calculate the time course of the release probability function per site. Figure $7 E$ shows $P_{\mathrm{R}}(t)$ for different extracellular $\left[\mathrm{Ca}^{2+}\right]$ values at this connection. Expressing the release functions as a cumulative probability shows that the majority of the release is completed by the peak of the EPSC (Fig. $7 E$, the $0.1 \mathrm{~ms}$ peak responses are indicated by gray line segments). The decline in the cumulative release function at $5 \mathrm{~mm}$ $\left[\mathrm{Ca}^{2+}\right]$ is likely to be an artifact caused by overcompensation of the spillover component at late times attributable to receptor desensitization (Fig. 2C). When the cumulative release functions were normalized to the peak of the direct response (Fig. $7 F$ ) and aligned on their $50 \%$ rise time (to account for changes in the latency), the shape of the $P_{\mathrm{R}}(t)$ functions was similar (Fig. $7 F$, inset), consistent with the results from latency measurements at single-site synapses.

The mean time course of the vesicular release rate per release site at $2 \mathrm{~mm}\left[\mathrm{Ca}^{2+}\right]$ across $14 \mathrm{MF}-\mathrm{GC}$ connections is shown in Figure $8 \mathrm{~A}$. The peak release rate per site varied from 0.6 to 5.5 vesicles/ms per site across connections in $2 \mathrm{mM}\left[\mathrm{Ca}^{2+}\right]$, and the mean was $2.8 \pm 1.8$ vesicles/ms per site. The mean vesicular release rate per site was increased to $6.6 \pm 2.5$ vesicles $/ \mathrm{ms}$ under high release probability conditions (in 5 or $8 \mathrm{mM}\left[\mathrm{Ca}^{2+}\right]$ ) and was strongly correlated with $P_{\mathrm{R}}$, as expected $(r=0.84 ; p<0.0001$; $n=14)$. The mean release time course had a fast rising phase (10-90\% rise time of $54 \mu \mathrm{s})$ and a slower falling phase with a single decay time constant of $75 \mu \mathrm{s}$. The full-width halfmaximum (FWHM) of the release time course, normalized to the $2 \mathrm{~mm}$ value, was not correlated with $\left[\mathrm{Ca}^{2+}\right]$ across the 14 cells examined ( $p=0.10$ ) (Fig. $8 B$ ). Moreover, there was no significant trend between the FWHM of the release time course and $P_{\mathrm{R}}$ 
measured at $2 \mathrm{~mm}$ across different MFs (data not shown; $r=-0.46 ; p=0.10$ ). Even when data from the different $\left[\mathrm{Ca}^{2+}\right]$ values and different MF connections were pooled, the relationship between the FWHM of the release time course and $P_{\mathrm{R}}$ was not correlated $(r=-0.28 ; p=0.06)$ (Fig. $8 C$ ). However, the correlation is on the border of significance: if there is correlation between these parameters that we cannot detect, the shallow slope of the fit indicates that the dependence of these parameters is weak. These results show that the peak release rate per site is large and that the time course of vesicular release is rapid at physiological temperature. Furthermore, the time course of vesicular release and $P_{\mathrm{R}}$ are not significantly correlated at the MF-GC synaptic connection.

\section{Simulations of individual EPSCs and model limitations}

We developed a simple stochastic model of MF synaptic transmission to test how well our measurements of release time course, quantal parameters, and spillover could account for EPSC variability and to investigate how these processes influence signaling. For these simulations, we used the quantal parameters for particular MF connections, obtained from MPFA in which $N$ was constrained to be an integer. The Monte Carlo simulation used the cellspecific mean quantal waveform, the population mean vesicular release time course, the population intrasite and intersite quantal variability, and the cellspecific mean waveform and amplitude distribution of spillover (see Materials and Methods). To assess how well our model reproduced the actual trial-to-trial EPSC variability, we compared real and simulated EPSCs. Figure $9 A$ shows the measured mean EPSC (top) and SD (bottom) from an input with five release sites and a $P_{\mathrm{R}}=0.46$ with the stochastic synaptic model of the same connection. The time course of the mean and SD of the simulated EPSCs was similar to that for the real EPSC for this and two other connections with small (1) and large (9) values of $N$. We then examined the distributions of EPSC peak amplitude, weighted decay, and charge transfer to assess how well our simple model could reproduce the measured data. Comparison of these distributions show considerable qualitative similarities between the simulated and observed data for this (Fig. 9B-D) and the two other connections (data not shown), indicating that the model reproduced much of the variability exhibited by EPSCs. However, quantitative comparison of
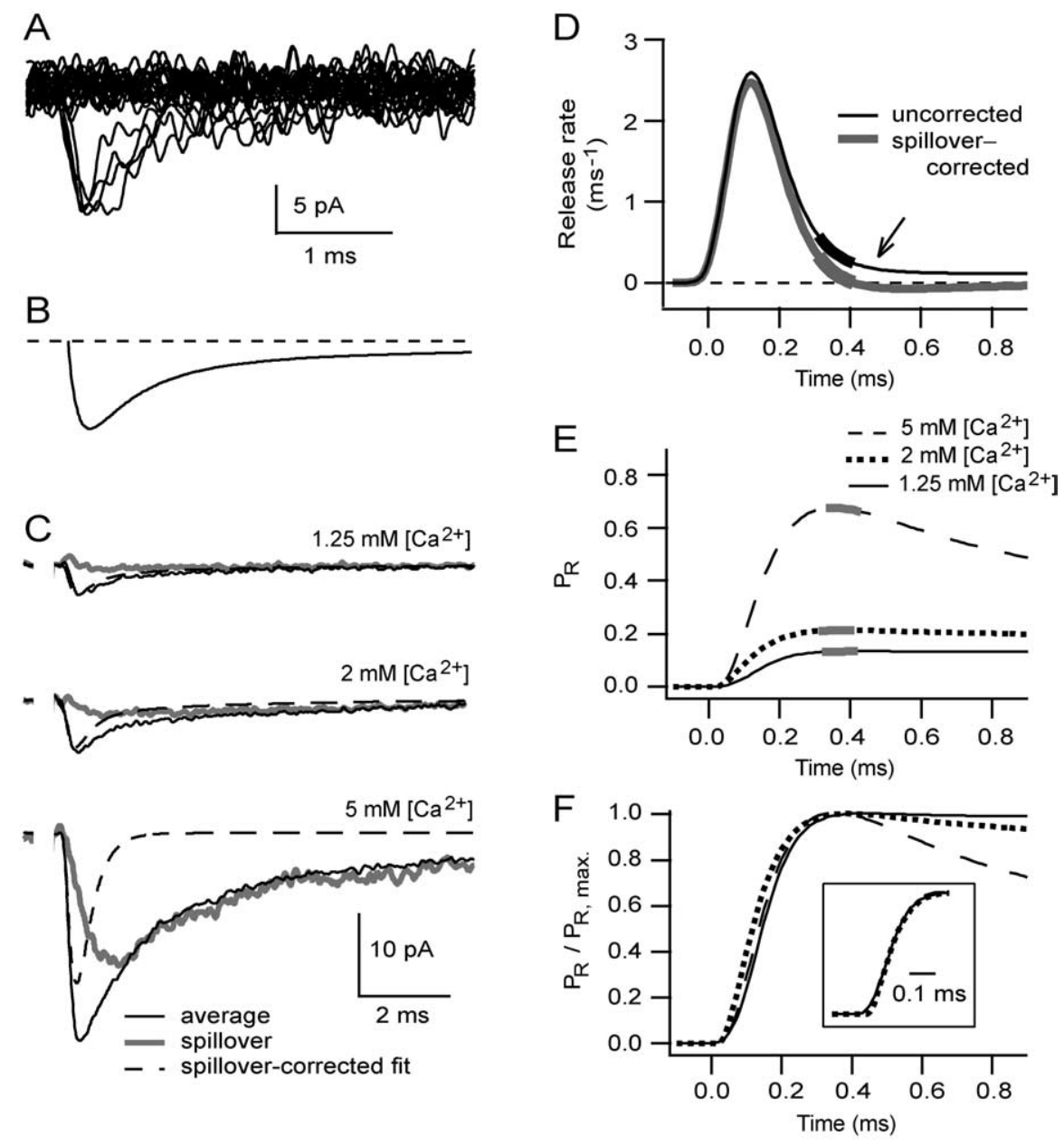

Figure 7. The time course of the probability of vesicular release estimated with deconvolution at MF-GC connections with multiple release sites. $\boldsymbol{A}$, A total of 24 consecutive responses to MF stimulation in $1.25 \mathrm{~mm}\left[\mathrm{Ca}^{2+}\right]$ (4 successes). $\boldsymbol{B}$, Fit of Equation 1 to the rise-aligned mean quantal waveform (for details, see Materials and Methods). $\boldsymbol{C}$, The average EPSC (black), average isolated spillover current (gray), and the fit of the spillover-corrected EPSC (dashed) for three $\left[\mathrm{Ca}^{2+}\right]$ values. D shows the deconvolved vesicular release time course for the uncorrected and spillover-corrected data at $2 \mathrm{~mm}\left[\mathrm{Ca}^{2+}\right]$. The thickened segments show the time of the $0.1 \mathrm{~ms}$ window at the peak of the direct response. $\boldsymbol{E}$ shows vesicular release probability as a function of time for spillover-corrected EPSCs at three $\left[\mathrm{Ca}^{2+}\right]$ values for this connection, which had an $N=2.2$. The thickened gray portion of the traces show the $0.1 \mathrm{~ms}$ peak of the direct response (the small shifts in peak times are related to differences in latency in different $\left[\mathrm{Ca}^{2+}\right]$ that are likely to be attributable to differences in fiber excitability; see Results). $\boldsymbol{F}$ shows the data in $\boldsymbol{E}$ normalized at the peak of the direct response. When the cumulative waveforms were aligned on their $50 \%$ rise ( $\boldsymbol{F}$, inset), their distributions were similar ( $p=0.99-1.00$ by pairwise Kolmogorov-Smirnov tests).
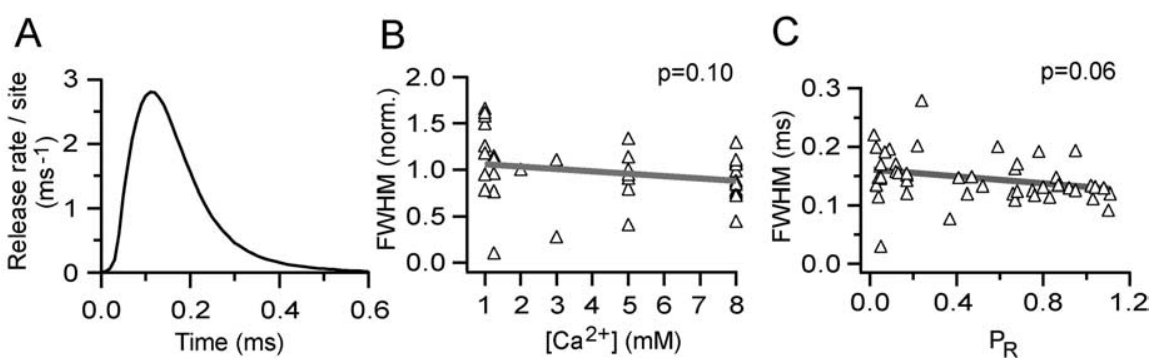

Figure 8. The time course of the vesicular release rate per site at MF-GC connections and its independence of $\left[\mathrm{Ca}^{2+}\right]$ and $P_{\mathrm{R}}$. $\boldsymbol{A}$ shows the average time course of vesicular release rate per release site estimated with deconvolution and MPFA from 14 MF-GC connections. The FWHM of the release function is $0.155 \mathrm{~ms}$, and $80 \%$ of the release occurs within $0.20 \mathrm{~ms}$. $\boldsymbol{B}$ shows the relationship between the FWHM of the release function, normalized to its value in $2 \mathrm{~mm}\left[\mathrm{Ca}^{2+}\right]$ for each cell and $\left[\mathrm{Ca}^{2+}\right]$. The solid line shows regression fit. $C$ shows the relationship between the FWHM of the vesicular release function and $P_{R^{\prime}}$ calculated from MPFA across 47 different $\left[\mathrm{Ca}^{2+}\right]$ runs from 14 connections. Solid line shows regression fit. 
A

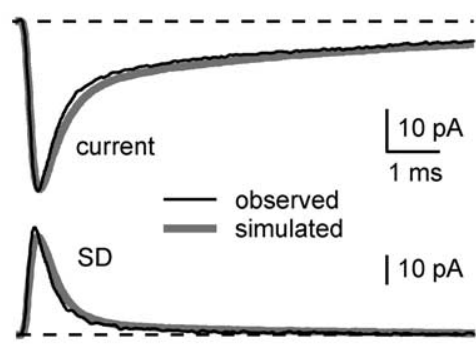

B

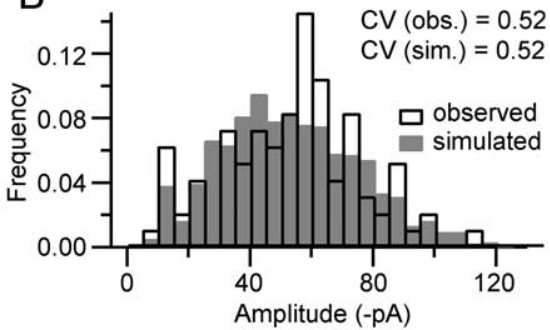

$\mathrm{C}$

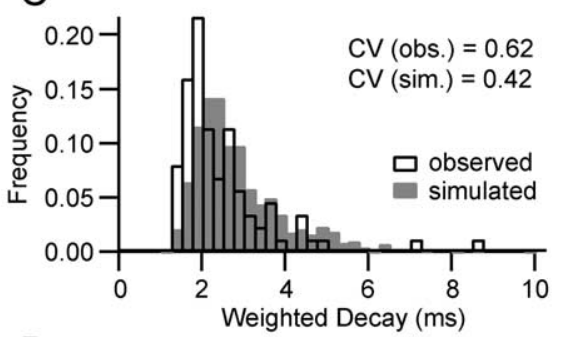

D

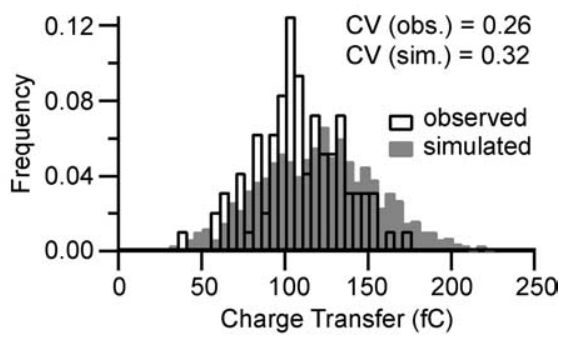

Figure 9. Simulations closely approximate the trial-to-trial variability in EPSC amplitude and shape. $A$ compares the mean EPSC (top) and SD (bottom) calculated from a sample of 96 EPSCs measured from an MF-GC synaptic connection (black line) and the mean EPSC and SD calculated from a sample of 1000 simulated EPSCs for this connection (gray line). The quantal parameters for this connection, $N=5$ and $P_{\mathrm{R}}=0.46$ at $2 \mathrm{~mm}\left[\mathrm{Ca}^{2+}\right]$, are similar to the population mean. $\boldsymbol{B}-\boldsymbol{D}$ compare real and simulated EPSCS for their peak amplitudes $(0.1 \mathrm{~ms}$ window; $\boldsymbol{B})$, weighted decay $(\boldsymbol{C})$, and charge transfer $(\boldsymbol{D})$.

several of the distributions using the sensitive KolmogorovSmirnov test revealed differences between the simulated and observed data. These discrepancies are likely to arise both from limiting sampling and nonlinear summation of quanta and spillover after the peak of the EPSC. These results suggest that the model can only approximate the real EPSC shape variability rather than reproduce it exactly. A more accurate model of transmission that took account of this nonlinear behavior would require a realistic model of the synaptic AMPARs, which is not available at present. Nevertheless, our simplified model, which provides a good approximation of the EPSC amplitude and shape variability, has allowed us to explore the influence of quantal variability and spillover on AMPAR-mediated EPSCs and EPSPs in GCs.

\section{Simulations investigating the influence of quantal variability on MF-GC synaptic signaling}

We first used our synaptic model to investigate the influence of quantal amplitude variability on MF signaling in the absence of spillover currents. Figure $10 \mathrm{~A} 1$ shows the simulated EPSCs from a single-site cell, in which the fraction of EPSC successes is equal to the vesicular release probability ( 0.22 in this case). To assess how these synaptic currents were integrated by GCs, we combined our synaptic model with a conductance-based singlecompartment model with GC-like membrane properties (see Materials and Methods). Because we are interested in the properties of an individual MF, but two or more MF EPSPs are required for the GC voltage to reach threshold from the resting potential (D'Angelo et al., 1995), we modulated the resting voltage by adding different levels of tonic excitatory conductance. Synaptic conductances from the single-site model produced EPSPs that were nearly $2 \mathrm{mV}$ in size (at a baseline membrane potential of $-52 \mathrm{mV}$ ) and invariant in amplitude (Fig. 10 A2). None of the EPSPs crossed an arbitrary threshold of $-50 \mathrm{mV}$. Inclusion of intrasite quantal amplitude variability $\left(\mathrm{CV}_{\mathrm{QS}}\right)$ in our simulation introduced large trial-to-trial fluctuations in EPSC amplitude but did not alter the mean EPSC amplitude (Fig. 10 B1). Simulated EPSPs also exhibited large-amplitude fluctuations, with some EPSPs crossing the $-50 \mathrm{mV}$ threshold at levels of baseline voltage that were subthreshold in the absence of quantal variance (Fig. 10, compare B2, A2).

To examine how quantal variability might influence synaptic integration, we estimated the reliability of synaptic integration by measuring the probability of crossing threshold $\left(P_{V}>\right.$ vthreshold $)$ from various resting voltages. In the absence of quantal variance, the $P_{V}>V$ threshold function had a discrete step, at $-52 \mathrm{mV}$, when it jumped to $P_{\mathrm{R}}$ (Fig. 10C, filled circles). In contrast, the presence of quantal variance introduced a graded relationship between $P_{V>V \text { threshold }}$ and the baseline voltage and extended the voltage range over which the EPSP could cross threshold (Fig. 10C, open triangles). This threshold smoothing effect of quantal variance is likely to be most pronounced at connections with a low quantal content $(<1)$, because threshold crossing function becomes less steplike as the number of vesicle released increases. To examine the influence of quantal variability on the latency of EPSP-spike coupling, we examined the SD of the time of the first threshold crossing. This parameter is a measure of the precision with which information can be transferred across synapses (Harsch and Robinson, 2000; Galarreta and Hestrin, 2001; Cathala et al., 2003). In the absence of quantal variance, there was little jitter in the time at which the threshold was crossed; this resulted in a small SD in the timing of threshold crossing (Fig. $10 \mathrm{D}$, filled circles). The presence of quantal variance broadened the distribution of threshold crossing times only slightly (Fig. $10 \mathrm{D}$, open triangles). These results show that quantal amplitude variability extends the voltage range over which EPSPs can cross threshold and that rapid vesicular release permits precise temporal signaling.

\section{Simulations investigating the influence of spillover on MF-GC synaptic signaling}

To assess the impact of spillover on synaptic signaling, we simulated three different MF inputs with a small (Fig. 11A1), mean (Fig. 11 B1), and large (Fig. 11C1) number of release sites. Inclusion of a spillover current component markedly increased trialto-trial variability in the shape of the EPSCs for the single-site connection, as can be seen by comparing Figures $10 \mathrm{~B} 1$ and $11 \mathrm{Al}$. The EPSP shape variability was also increased when spillover was included, with the peaks occurring later when the direct release failed (Figs. 10 B2, 11A2). EPSC and EPSP shape variability was also pronounced in connections with intermediate numbers of release sites but became less pronounced in the connection with many release sites (Fig. 11B1,B2,C1,C2). A comparison of the probability of threshold crossing $\left(P_{V}>V\right.$ threshold $)$ as a function of baseline voltage for simulations with and without the spillover shows that spillover increases the reliability of signaling by shifting the relationship to hyperpolarized voltages (Fig. 11A3). Although this effect was substantial across all of the MFs simulated (Fig. 11A3,B3,C3), the EPSPs from the strongest connections were still insufficient to cross threshold from a resting potential of 
$-80 \mathrm{mV}$ (Cathala et al., 2003), consistent with the proposal that at least two MFs are required to fire a GC (D'Angelo et al., 1995). At synapses in which failures in quantal release occurred, the presence of spillover increased $P_{V>V \text { threshold }}$ from the maximal level attainable for quantal release $(1-f)$ to $\sim 1$ at depolarized potentials (Fig. 11A3). We showed previously that spillover broadens the mean EPSP, increasing its half-width by $50 \%$ (DiGregorio et al., 2002). Our simulations show that EPSP broadening and shape variability also tend to broaden the distribution of threshold crossing times, increasing the SD (Fig. 11A4-C4, compare open and filled symbols). This effect was baseline voltage dependent and generally smaller at hyperpolarized voltages. Even at the peak of the effect, the values of the SD in the threshold crossing time were small $(<500$ $\mu$ s across the different connections). These results show that spillover substantially increases the reliability of transmission and rapid vesicular release, and fast quantal currents permit relatively precise signaling at the MF-GC synapse.

\section{Discussion}

\section{Vesicular release and summation}

of quanta

Multivesicular release at climbing fiber and calyx of Held synapses can lead to nonlinear quantal summation attributable to AMPA receptor saturation (Meyer et al., 2001; Foster et al., 2002; Harrison and Jahr, 2003). At the MF-GC synapse, our experiments using a rapidly equilibrating competitive antagonist show that quantal events sum linearly at the peak of the EPSC even at high $P_{\mathrm{R}}$. This finding could be accounted for by either the release of a maximum of one quantum at each PSD or the release of multiple vesicles per PSD if AMPAR occupancy is low during a quantal event. Several observations indicate that AMPAR occupancy is well below saturation at the MF-GC synapse: approximately linear summation of quanta and spillover currents at single-site synapses, high intrasite quantal variance, and potentiation of the quantal response when diffusion is slowed (Nielsen et al., 2004). Although it is therefore possible that more than one vesicle is released per synaptic contact at multisite MF synaptic connections, our competitive antagonist experiments suggest that, if present, multivesicular release makes a much smaller contribution than at the climbing fiber (Wadiche and Jahr, 2001; Foster and Regehr, 2004). Indeed, the occurrence of single-site MF connections with EPSC successes that are constant in amplitude over a wide range of $P_{\mathrm{R}}$ values indicates that at least some MF-GC synapses operate in the univesicular mode. Moreover, the area of MF-GC active zones is much smaller than at synapses in which multivesicular release has been reported (Zucker and Regehr, 2002), providing limited space for docked vesicles. Our estimate of $N$ is comparable with the mean number of anatomical PSDs on a GC dendrite
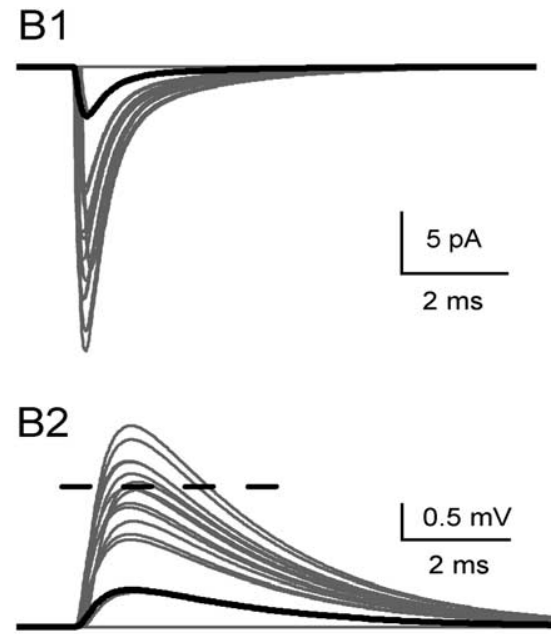

D

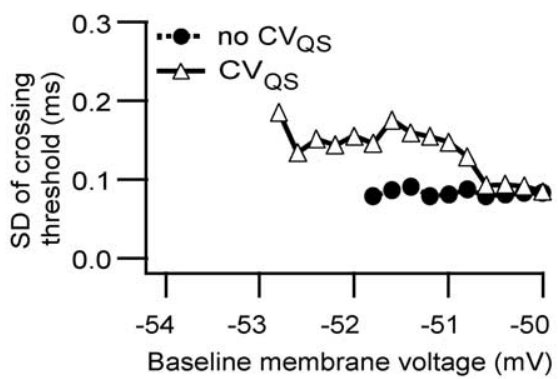

Figure 10. Simulations suggest that quantal variance smoothes spike threshold by extending the range of voltages from which

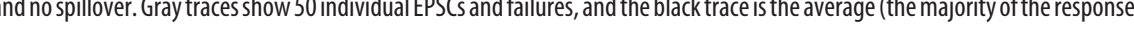
were failures). $\boldsymbol{A} \mathbf{2}$ shows simulated EPSPs for the same currents as in $\mathbf{A} \mathbf{1}$ for a passive single-compartment model with a baseline syme probability over 1000 trials; filled circles show the relationship with no quantal variance, and open triangles show the relationship in the presence of quantal variance. D shows the relationship between the SD of the times at which the EPSP crossed the $-50 \mathrm{mV}$ threshold and the baseline voltage. Each symbol represents the SD calculated over 1000 trials.

(4.7 and $\sim 6$, respectively) (Jakab and Hamori, 1988; XuFriedman and Regehr, 2003). This approximate one-to-one relationship and the fact that the AMPARs operate in their linear range suggest that univesicular release predominates at MF-GC connections.

The finding that the EPSC variance is reduced at high $P_{\mathrm{R}}$, under conditions of linear quantal summation, suggests that the number of vesicles released per site per AP is restricted. At the calyx of Held, three vesicles can be released per PSD during a 10 ms depolarizing pulse (Sun and $\mathrm{Wu}, 2001$ ), which suggests either that a restriction on vesicular release is absent or that prolonged calcium waveforms are sufficient to overcome such a barrier. The simplest explanation of our data are that only one vesicle is release ready at each release site and that the replenishment rate is much slower than the vesicular release time course after an AP.

Time course, rate, and probability of vesicular release

We quantified the time course of vesicular release from individual MF connections at physiological temperature. The release rate rises rapidly ( $54 \mu$ s $10-90 \%$ rise time), and the decay of the vesicular release time course is fast $(\tau=75 \mu \mathrm{s})$ compared with the 150-300 $\mu$ s observed at other synapses at near body temperature 
$\mathrm{N}=1$

A1
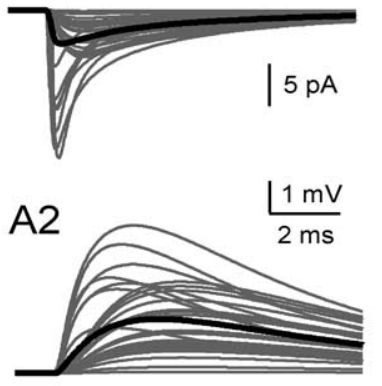

.•-.. CV $\mathrm{CV}_{\mathrm{QS}}$ no spillover $\neg-C V_{Q S}$ spillover

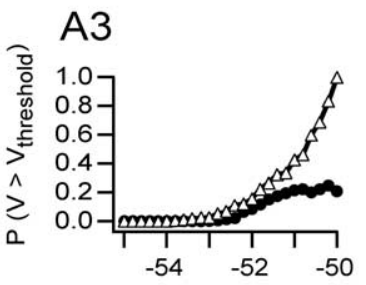

\section{A4}

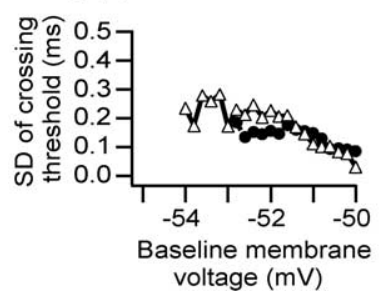

$\mathrm{N}=5$
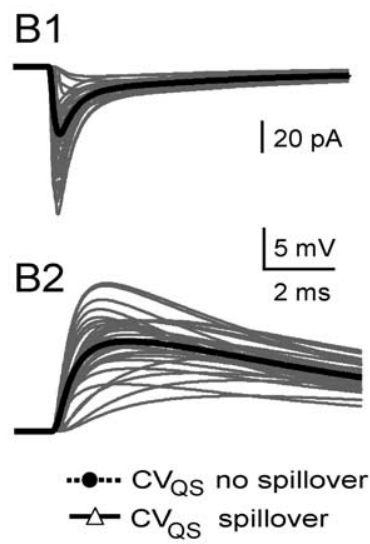

B3

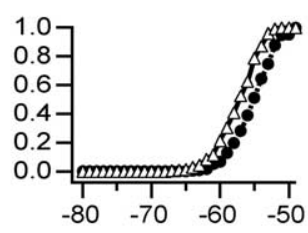

B4

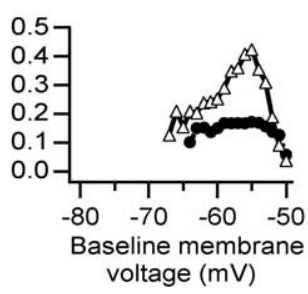

$N=9$
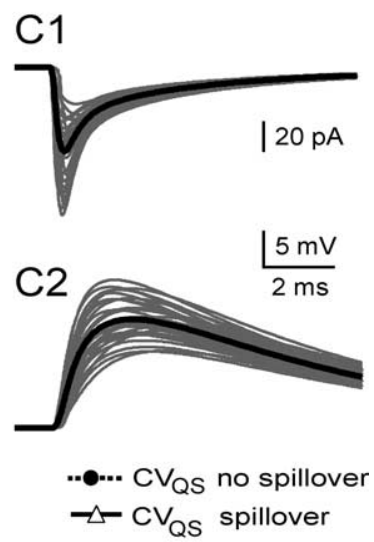

C3

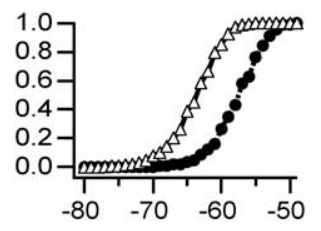

\section{C4}

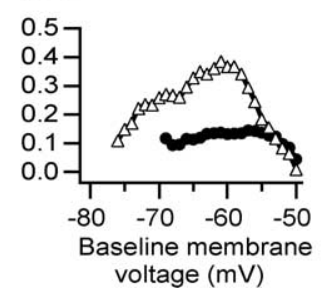

(Fedchyshyn and Wang, 2005), or if the intracellular $\left[\mathrm{Ca}^{2+}\right]$ is shaped by buffers (Meinrenken et al., 2002). However, we cannot rule out the possibility of some calciumdependent speeding of release (Felmy et al., 2003; Bollmann and Sakmann, 2005) if it were masked by a calcium-dependent broadening of the AP (Schneggenburger et al., 1999). Because the release time course is rapid compared with the miniature EPSC, estimates of $P_{\mathrm{R}}$ from MPFA at the peak of the quantal response will correspond to the final release probability.

Our results indicate that the peak vesicular release rate per site after an $\mathrm{AP}$ is $\sim 3$ $\mathrm{ms}^{-1}$ at physiological temperature. This is an order of magnitude higher than the peak release rate at the calyx of Held at room temperature, $0.2-0.4 \mathrm{~ms}^{-1}$ (Bollmann et al., 2000; Schneggenburger and Neher, 2000), but this difference may arise principally from differences in temperature, given the high $Q_{10}$ of the release time course (2-3) (Isaacson and Walmsley, 1995; Silver et al., 1996b). $P_{\mathrm{R}}$, which is the integral of the release function, is approximately twofold lower at the calyx. As extracellular $\left[\mathrm{Ca}^{2+}\right]$ was increased at the MF, the peak vesicular release rate per site reached 7 $\mathrm{ms}^{-1}$ after an AP. This may be close to the maximal rate that can be achieved, given the rapid time course and the fact that $P_{\mathrm{R}} \rightarrow 1$ under these conditions.

\section{Rapid vesicular release and temporal precision}

The brief window for release at the MF synapse will tend to minimize jitter in the EPSC latency, especially at connections with few release sites or low $P_{\mathrm{R}}$. This property, together with the rapid time course of the quantal events (Silver et al., 1992; Cathala et al., 2003), produces timelocked EPSPs with rapid rise times. How-

$\left(30-34^{\circ} \mathrm{C}\right)$ (Isaacson and Walmsley, 1995; Geiger et al., 1997). Indeed, the duration of vesicular release at the MF is comparable with the duration of calcium entry at $37^{\circ} \mathrm{C}$ at other synapses (Borst and Sakmann, 1998; Geiger and Jonas, 2000). Although this correlation might suggest that the calcium current time course determines the release waveform via a rapid equilibration with the calcium sensor, the release time course generated by such a mechanism would be expected to speed as $\left[\mathrm{Ca}^{2+}\right]$ increased when only one, rather than a large number of, vesicles is available for immediate release per site. The simplest explanation for our results is that the reaction is far from equilibrium and that processes downstream of calcium binding determine the release time course. Indeed, it has been shown recently that, when the intracellular $\left[\mathrm{Ca}^{2+}\right]$ transient becomes brief, the release time course becomes independent of the transient duration, suggesting that conformational changes in the release machinery can be rate limiting (Bollmann and Sakmann, 2005). Such rapid calcium transients could be experienced by the calcium sensor if it is within tens of nanometers of the entry site ["nanodomains" (Neher, 1998)], as reported recently ever, our simulations suggest that the temporal precision achievable at this synapse is reduced by the EPSC shape variability introduced by an intermediate $P_{\mathrm{R}}$, quantal variability, and slow spillover currents. In practice, this tradeoff between timing and reliability may not compromise temporal signaling, because simulations suggest that the SD of the time of threshold crossing is $<500 \mu$ s and that precision improves at hyperpolarized potentials; this value compares with the $\sim 400 \mu$ s SD of EPSP latencies at cortical connections (Feldmeyer et al., 2002), which are tuned for temporal signaling (Silver et al., 2003). Moreover, the insensitivity of the release time course to $P_{\mathrm{R}}$ may allow temporal signaling to be maintained across connections with a wide distribution of synaptic weights, during presynaptic modulation by neurotransmitter (Mitchell and Silver, 2000) and activitydependent plasticity (Sola et al., 2004).

\section{Quantal variability, spillover, and reliability}

Our results suggest that spillover currents could contribute to rate-coded signaling by enhancing reliability at MF-GC connec- 
tions. This property, together with the quantal variability at this synapse, allows single-fiber EPSPs to reach threshold from more hyperpolarized voltage levels, increasing reliability and allowing small inputs to have a greater effect on some trials but less on others. For a single MF, spillover currents will also increase the window for temporal integration, thus lowering the burst frequency necessary to produce GC firing, a property observed in vivo (Chadderton et al., 2004). Moreover, by introducing substantial trial-to-trial variability in the EPSP, spillover and quantal variance tend to smooth the interaction between the EPSP and AP threshold for time-averaged measures of activity, thereby linearizing the effects of the excitatory input.

\section{Implications for cerebellar processing}

Our results show that large fiber-to-fiber variation in MF synaptic strength arises from differences in the quantal parameters: $N$, $P_{\mathrm{R}}$, and $\mathrm{Q}$, and from glutamate spillover. However, our results suggest that $P_{\mathrm{R}}$ is relatively uniform across the 200-400 release sites (Xu-Friedman and Regehr, 2003) on an individual MF terminal, as observed recently at cortical connections (Koester and Johnston, 2005). Variation in $P_{\mathrm{R}}$ across fibers could arise from a number of sources, but if presynaptic long-term potentiation (Sola et al., 2004) contributes to the high $P_{\mathrm{R}}$ we observe at a fraction of connections (Fig. $5 C$ ), then our results suggest that the specificity of this plasticity is at the level of a whole terminal rather than an individual GC. Our observations, combined with data on plasticity (Sola et al., 2004) and modulation (Mitchell and Silver, 2000), suggest that $P_{\mathrm{R}}$ is a "global variable" that alters the synaptic efficacy at all of the 50 GCs connected to an MF terminal.

We have shown that the mathematical operations that inhibition performs on rate-coded signals depend on the variance of the synaptic input, with noise permitting inhibition-mediated multiplicative scaling (gain modulation) (Mitchell and Silver, 2003). The large trial-to-trial variability in amplitude and shape of MF EPSCs arising from quantal release, quantal variability, and spillover will contribute to the variance of synaptic input trains. Moreover, the mean $P_{\mathrm{R}}$ at the $\mathrm{MF}(\sim 0.5)$ is set at a level that maximizes the variance arising from stochastic release. It therefore seems that the stochastic properties of the synapse are well suited to allow multiplicative scaling of rate-coded signals by the tonic inhibition in these cells (Semyanov et al., 2004). This, together with the enhanced reliability of spillover and threshold smoothing by quantal variance, is likely to increase the dynamic range of rate-coded signaling.

The cerebellum is thought to be involved in coordinating movements, which requires precise timing. It is therefore likely that timing information is conveyed by MFs. Highly synchronized vesicular release and brief quantal currents (Silver et al., 1992, 1996a; Cathala et al., 2003) are well suited for such temporal signaling. When local groups of MFs are active, the pattern of $\mathrm{GC}$ firing in a region will be determined by the strength of the MF connections and by correlations in the MF activity. Previous theoretical work suggests that inputs with larger $N$ and higher $P_{\mathrm{R}}$ may dominate, because they are capable of transmitting information at higher rates than weaker connections (Zador, 1998). By synchronizing quantal release and by improving the reliability of excitatory drive, synchronized release and spillover are likely to increase the fraction of active GCs. This may allow temporal correlations across multiple local MFs to be transmitted through the GC layer as intense "patches" of synchronized activity, while allowing rate-coded signals to be mediated by lower intensity, uncorrelated GC activity.

\section{References}

Barrett EF, Stevens CF (1972) The kinetics of transmitter release at the frog neuromuscular junction. J Physiol (Lond) 227:691-708.

Bekkers JM, Clements JD (1999) Quantal amplitude and quantal variance of strontium-induced asynchronous EPSCs in rat dentate granule neurons. J Physiol (Lond) 516:227-248.

Bekkers JM, Stevens CF (1996) Cable properties of cultured hippocampal neurons determined from sucrose-evoked miniature EPSCs. J Neurophysiol 75:1250-1255.

Bekkers JM, Richerson GB, Stevens CF (1990) Origin of variability in quantal size in cultured hippocampal neurons and hippocampal slices. Proc Natl Acad Sci USA 87:5359-5362.

Bollmann JH, Sakmann B (2005) Control of synaptic strength and timing by the release-site $\mathrm{Ca}^{2+}$ signal. Nat Neurosci 8:426-434.

Bollmann JH, Sakmann B, Borst JG (2000) Calcium sensitivity of glutamate release in a calyx-type terminal. Science 289:953-957.

Borst JG, Sakmann B (1996) Calcium influx and transmitter release in a fast CNS synapse. Nature 383:431-434.

Borst JG, Sakmann B (1998) Calcium current during a single action potential in a large presynaptic terminal of the rat brainstem. J Physiol (Lond) 506:143-157.

Borst JG, Lodder JC, Kits KS (1994) Large amplitude variability of GABAergic IPSCs in melanotropes from Xenopus laevis: evidence that quantal size differs between synapses. J Neurophysiol 71:639-655.

Borst JG, Helmchen F, Sakmann B (1995) Pre- and postsynaptic whole-cell recordings in the medial nucleus of the trapezoid body of the rat. J Physiol (Lond) 489:825-840.

Cathala L, Misra C, Cull-Candy S (2000) Developmental profile of the changing properties of NMDA receptors at cerebellar mossy fiber-granule cell synapses. J Neurosci 20:5899-5905.

Cathala L, Brickley S, Cull-Candy S, Farrant M (2003) Maturation of EPSCs and intrinsic membrane properties enhances precision at a cerebellar synapse. J Neurosci 23:6074-6085.

Chadderton P, Margrie TW, Hausser M (2004) Integration of quanta in cerebellar granule cells during sensory processing. Nature 428:856-860.

Chen C, Regehr WG (1999) Contributions of residual calcium to fast synaptic transmission. J Neurosci 19:6257-6266.

Clements JD, Silver RA (2000) Unveiling synaptic plasticity: a new graphical and analytical approach. Trends Neurosci 23:105-113.

Cohen I, van der Kloot W, Attwell D (1981) The timing of channel opening during miniature end-plate currents. Brain Res 223:185-189.

D’Angelo E, De Filippi G, Rossi P, Taglietti V (1995) Synaptic excitation of individual rat cerebellar granule cells in situ: evidence for the role of NMDA receptors. J Physiol (Lond) 484:397-413.

Diamond JS, Jahr CE (1995) Asynchronous release of synaptic vesicles determines the time course of the AMPA receptor-mediated EPSC. Neuron 15:1097-1107.

DiGregorio DA, Nusser Z, Silver RA (2002) Spillover of glutamate onto synaptic AMPA receptors enhances fast transmission at a cerebellar synapse. Neuron 35:521-533.

Faber DS, Young WS, Legendre P, Korn H (1992) Intrinsic quantal variability due to stochastic properties of receptor-transmitter interactions. Science 258:1494-1498.

Fedchyshyn MJ, Wang LY (2005) Developmental transformation of the release modality at the calyx of held synapse. J Neurosci 25:4131-4140.

Feldmeyer D, Lubke J, Silver RA, Sakmann B (2002) Synaptic connections between layer 4 spiny neurone-layer $2 / 3$ pyramidal cell pairs in juvenile rat barrel cortex: physiology and anatomy of interlaminar signalling within a cortical column. J Physiol (Lond) 538:803-822.

Felmy F, Neher E, Schneggenburger R (2003) The timing of phasic transmitter release is $\mathrm{Ca}^{2+}$-dependent and lacks a direct influence of presynaptic membrane potential. Proc Natl Acad Sci USA 100:15200-15205.

Forti L, Bossi M, Bergamaschi A, Villa A, Malgaroli A (1997) Loose-patch recordings of single quanta at individual hippocampal synapses. Nature 388:874-878.

Foster KA, Regehr WG (2004) Variance-mean analysis in the presence of a rapid antagonist indicates vesicle depletion underlies depression at the climbing fiber synapse. Neuron 43:119-131.

Foster KA, Kreitzer AC, Regehr WG (2002) Interaction of postsynaptic receptor saturation with presynaptic mechanisms produces a reliable synapse. Neuron 36:1115-1126.

Frerking M, Wilson M (1999) Differences in uniquantal amplitude between 
sites reduce uniquantal variance when few release sites are active. Synapse 32:276-287.

Frerking M, Borges S, Wilson M (1995) Variation in GABA mini amplitude is the consequence of variation in transmitter concentration. Neuron 15:885-895.

Galarreta M, Hestrin S (2001) Spike transmission and synchrony detection in networks of GABAergic interneurons. Science 292:2295-2299.

Geiger JR, Jonas P (2000) Dynamic control of presynaptic $\mathrm{Ca}^{2+}$ inflow by fast-inactivating $\mathrm{K}^{+}$channels in hippocampal mossy fiber boutons. Neuron 28:927-939.

Geiger JR, Lubke J, Roth A, Frotscher M, Jonas P (1997) Submillisecond AMPA receptor-mediated signaling at a principal neuron- interneuron synapse. Neuron 18:1009-1023.

Hamori J, Somogyi J (1983) Differentiation of cerebellar mossy fiber synapses in the rat: a quantitative electron microscope study. J Comp Neurol 220:365-377.

Harrison J, Jahr CE (2003) Receptor occupancy limits synaptic depression at climbing fiber synapses. J Neurosci 23:377-383.

Harsch A, Robinson HP (2000) Postsynaptic variability of firing in rat cortical neurons: the roles of input synchronization and synaptic NMDA receptor conductance. J Neurosci 20:6181-6192.

Isaacson JS, Walmsley B (1995) Counting quanta: direct measurements of transmitter release at a central synapse. Neuron 15:875-884.

Jakab RL, Hamori J (1988) Quantitative morphology and synaptology of cerebellar glomeruli in the rat. Anat Embryol 179:81-88.

Katz B (1969) The release of neural transmitter substances. Liverpool, UK: Liverpool UP.

Koester HJ, Johnston D (2005) Target cell-dependent normalization of transmitter release at neocortical synapses. Science 308:863-866.

Liu G, Choi S, Tsien RW (1999) Variability of neurotransmitter concentration and nonsaturation of postsynaptic AMPA receptors at synapses in hippocampal cultures and slices. Neuron 22:395-409.

Meinrenken CJ, Borst JG, Sakmann B (2002) Calcium secretion coupling at calyx of held governed by nonuniform channel-vesicle topography. J Neurosci 22:1648-1667.

Meyer AC, Neher E, Schneggenburger R (2001) Estimation of quantal size and number of functional active zones at the calyx of held synapse by nonstationary EPSC variance analysis. J Neurosci 21:7889-7900.

Mitchell SJ, Silver RA (2000) GABA spillover from single inhibitory axons suppresses low-frequency excitatory transmission at the cerebellar glomerulus. J Neurosci 20:8651-8658.

Mitchell SJ, Silver RA (2003) Shunting inhibition modulates neuronal gain during synaptic excitation. Neuron 38:433-445.

Neher E (1998) Vesicle pools and $\mathrm{Ca}^{2+}$ microdomains: new tools for understanding their roles in neurotransmitter release. Neuron 20:389-399.

Neher E, Sakaba T (2001) Combining deconvolution and noise analysis for the estimation of transmitter release rates at the calyx of held. J Neurosci 21:444-461.

Nielsen TA, DiGregorio DA, Silver RA (2004) Modulation of glutamate mobility reveals the mechanism underlying slow-rising AMPAR EPSCs and the diffusion coefficient in the synaptic cleft. Neuron 42:757-771.

Nusser Z, Naylor D, Mody I (2001) Synapse-specific contribution of the variation of transmitter concentration to the decay of inhibitory postsynaptic currents. Biophys J 80:1251-1261.

Oertner TG, Sabatini BL, Nimchinsky EA, Svoboda K (2002) Facilitation at single synapses probed with optical quantal analysis. Nat Neurosci 5:657-664.

Palay SL, Chan-Palay V (1974) Cerebellar cortex: cortex and organization. New York: Springer.

Press WH, Teukolsky SA, Vetterling WT, Flannery BP (1994) Numerical recipes in C, Ed 2. Cambridge, UK: Cambridge UP.
Reid CA, Clements JD (1999) Postsynaptic expression of long-term potentiation in the rat dentate gyrus demonstrated by variance-mean analysis. J Physiol (Lond) 518:121-130.

Schneggenburger R, Neher E (2000) Intracellular calcium dependence of transmitter release rates at a fast central synapse. Nature 406:889-893.

Schneggenburger R, Meyer AC, Neher E (1999) Released fraction and total size of a pool of immediately available transmitter quanta at a calyx synapse. Neuron 23:399-409.

Semyanov A, Walker MC, Kullmann DM, Silver RA (2004) Tonically active $\mathrm{GABA}_{\mathrm{A}}$ receptors: modulating gain and maintaining the tone. Trends Neurosci 27:262-269.

Silver RA (2003) Estimation of nonuniform quantal parameters with multiple-probability fluctuation analysis: theory, application and limitations. J Neurosci Methods 130:127-141.

Silver RA, Traynelis SF, Cull-Candy SG (1992) Rapid-time-course miniature and evoked excitatory currents at cerebellar synapses in situ. Nature 355:163-166.

Silver RA, Colquhoun D, Cull-Candy SG, Edmonds B (1996a) Deactivation and desensitization of non-NMDA receptors in patches and the time course of EPSCs in rat cerebellar granule cells. J Physiol (Lond) 493:167-173.

Silver RA, Cull-Candy SG, Takahashi T (1996b) Non-NMDA glutamate receptor occupancy and open probability at a rat cerebellar synapse with single and multiple release sites. J Physiol (Lond) 494:231-250.

Silver RA, Momiyama A, Cull-Candy SG (1998) Locus of frequencydependent depression identified with multiple-probability fluctuation analysis at rat climbing fibre-Purkinje cell synapses. J Physiol (Lond) 510:881-902.

Silver RA, Lubke J, Sakmann B, Feldmeyer D (2003) High-probability uniquantal transmission at excitatory synapses in barrel cortex. Science 302:1981-1984.

Sola E, Prestori F, Rossi P, Taglietti V, D’Angelo E (2004) Increased neurotransmitter release during long-term potentiation at mossy fibre-granule cell synapses in rat cerebellum. J Physiol (Lond) 557:843-861.

Stevens CF, Wang Y (1995) Facilitation and depression at single central synapses. Neuron 14:795-802.

Sun JY, Wu LG (2001) Fast kinetics of exocytosis revealed by simultaneous measurements of presynaptic capacitance and postsynaptic currents at a central synapse. Neuron 30:171-182.

Sun JY, Wu XS, Wu LG (2002) Single and multiple vesicle fusion induce different rates of endocytosis at a central synapse. Nature 417:555-559.

Traynelis SF, Silver RA, Cull-Candy SG (1993) Estimated conductance of glutamate receptor channels activated during EPSCs at the cerebellar mossy fiber-granule cell synapse. Neuron 11:279-289.

Van der Kloot W (1988) Estimating the timing of quantal releases during end-plate currents at the frog neuromuscular junction. J Physiol (Lond) 402:595-603.

Wadiche JI, Jahr CE (2001) Multivesicular release at climbing fiberPurkinje cell synapses. Neuron 32:301-313.

Wall MJ, Usowicz MM (1998) Development of the quantal properties of evoked and spontaneous synaptic currents at a brain synapse. Nat Neurosci 1:675-682.

Xu-Friedman MA, Regehr WG (2003) Ultrastructural contributions to desensitization at cerebellar mossy fiber to granule cell synapses. J Neurosci 23:2182-2192.

Zador A (1998) Impact of synaptic unreliability on the information transmitted by spiking neurons. J Neurophysiol 79:1219-1229.

Zucker RS, Regehr WG (2002) Short-term synaptic plasticity. Annu Rev Physiol 64:355-405. 